\title{
Assessment of the Thermal Properties of Aromatic Esters as Novel Phase Change Materials
}

\author{
Rebecca Ravotti *(1), Oliver Fellmann, Ludger J. Fischer@, Jörg Worlitschek $₫$ and \\ Anastasia Stamatiou \\ Competence Centre Thermal Energy Storage (TES), Lucerne University of Applied Sciences and Arts, \\ 6048 Horw, Switzerland; oliver.fellmann@hslu.ch (O.F.); ludger.fischer@hslu.ch (L.J.F.); \\ joerg.worlitschek@hslu.ch (J.W.); anastasia.stamatiou@hslu.ch (A.S.) \\ * Correspondence: rebecca.ravotti@hslu.ch
}

Received: 21 August 2020; Accepted: 8 October 2020; Published: 10 October 2020

check for updates

\begin{abstract}
In the quest for a decarbonized energy system, the development of highly efficient technologies that allow the integration of renewables is of the utmost importance. Latent Heat Storage systems with Phase Change Materials (PCM) can contribute to solving the issue of the mismatch between demand and supply brought forward by renewable energies. Despite possessing promising thermal properties, organic PCMs and esters in particular have rarely been investigated. In the present study, eight commercial aromatic esters are assessed as possible PCM candidates. To do so, their thermal properties, such as phase change temperature, enthalpy of fusion, density, and thermal conductivity, alongside sustainability and toxicity issues, are considered. The aromatic esters are found to possess phase change temperatures between $-16^{\circ} \mathrm{C}$ and $190{ }^{\circ} \mathrm{C}$ and maximum enthalpies of fusion of $160 \mathrm{~J} / \mathrm{g}$. This, alongside densities above $1 \mathrm{~g} / \mathrm{mL}$, makes them interesting candidates for high-temperature applications, where, typically, salts and ceramics or metals dominate as PCMs.
\end{abstract}

Keywords: phase change materials; esters, aromatic ester; thermal energy storage; latent heat storage; thermal properties; PCM; LHS; TES

\section{Introduction}

In view of the future process of decarbonization to grant a more sustainable future less dependent on fossil fuels, a progressive integration of renewable energy in the actual energy systems is currently taking place. However, renewables such as wind and solar power are inevitably subjected to fluctuations which often do not match the consumers' demand. For this reason, problems related to overdemand or oversupply might arise if methods to store and increase the flexibility of renewables are not developed [1-3].

Thermal Energy Storage (TES) systems have gained interest owing to their ability to cover for the mismatch between demand and supply and to provide higher flexibility, especially in those applications where the end user requires thermal energy at different temperature levels. Among these, Latent Heat Storage (LHS) systems provide more compact solutions by exploiting the ability of Phase Change Materials (PCM) to store and release both latent and sensible heat of fusion during a phase change transition $[4,5]$.

To ensure high performances of the LHS system, the choice of the appropriate PCM is of utmost importance. To date, the most widely used organic and inorganic PCMs are paraffins and salt hydrates, respectively. While both are commercially available and generally characterized by low prices, they still present several disadvantages such as flammability, segregation or supercooling. Therefore, several studies on alternative materials to be used as a PCM are currently being carried out by researchers [6]. 
Esters are organic compounds obtained by the combination of alcohol and carboxylic acid molecules. Therefore, ideally, millions of combinations between these two species are possible, to create esters with unique properties. Esters also occur widely in nature and can be commonly found in plants, fruits and animal or vegetable fat [7]. From a chemical point of view, esters are typically characterized by low reactivity and high chemical stability, low or no toxicity and no corrosivity [8]. However, despite such interesting properties, only limited data exist on their thermal properties.

Due to the infinite combinations possible between acids and alcohols, esters can be divided into subclasses based on their chemical structures and groups. Fatty esters, or esters derived from fatty alcohols or fatty acids, have been subjected to more intensive studies compared to other subclasses [9-12]. Such studies revealed attractive properties in terms of narrow phase change transitions and reproducibility over consecutive heating cooling cycles. The melting points of fatty esters are generally found in a low- to mid-temperature range from 0 to $60^{\circ} \mathrm{C}$, while the enthalpies of fusion usually present comparable values to those of paraffins between 150 and $200 \mathrm{~J} / \mathrm{g}$. While fatty esters are attractive PCMs for low- to mid-temperature applications, their properties make them unsuitable for higher temperature applications [11,12].

Another subclass of esters which has been investigated intensively, albeit mostly for applications connected to the food industry, is that of triglycerides. In this case, most studies focused on the modelling or prediction of thermal properties based on the chemical structures. While triglycerides are generally characterized by higher temperatures compared to fatty esters, to date, their tendency to undergo polymorphism has deemed them unsuitable for LHS applications [13-15].

Esters suitable for higher temperature LHS applications are still to be discovered. Aromatic esters are a subclass of esters characterized by the presence of one or more aromatic rings within their chemical structure. Aromatic compounds usually present extreme stabilities due to the delocalized electron density shared between all atoms in the aromatic ring, and due to the ability of the rings to stack in closely packed structures commonly referred to as $\pi-\pi$ stacking [16]. This gives rise to more stable structures, which would ideally lead to higher melting points. For this reason, aromatic esters might be interesting candidates for higher temperature applications. Very few data on the thermal properties of aromatic esters are available, and no data on their behaviour in terms of reproducibility over consecutive heating/cooling cycles in view of LHS applications were found.

In this study, the authors measured the thermal properties of eight commercial aromatic esters Dibenzyl oxalate (DBO), Dimethyl-2,6-naphthalene dicarboxylate (2,6-DMNDC), Anysil acetate (AnAc), Methyl-2-methoxybenzoate (Me-2-MeBe), Benzyl benzoate (BEB), Dimethyl terephthalate (DiMeOHTe), Methyl-2-furoate (Me-2-Fu) and Phenyl benzoate (PHB) and assessed their suitability as PCM for LHS applications. Their chemical structures, IUPAC names and abbreviations are reported in Figure 1.

The compounds were selected based on several factors, such as their commercial availability, natural occurrence, chemical structure or correlation to other compounds investigated in previous studies by the authors. For example, 2,6-DMNDC, DiMeOHTe and DBO are both aromatic esters and diesters, and, as such, can be compared between each other and with fatty diesters [17]. Me-2-Fu, $\mathrm{BeB}$ and AnAc all occur widely in nature [18,19]. PHB is characterized by almost the same chemical structure as BEB, with a Benzyl substitute group instead of a Phenyl. Therefore, the properties of these two esters can be compared. Although they do not occurr in nature, DiMeOHTe and 2,6-DMNDC are widely used in the industry as monomers for the synthesis of plastics $[20,21]$, thus they could possibly be extracted from recycled material [22]. Finally, Me-2-MeBe has a similar structure to that of AnAc, with an additional carbon in the carboxylic group and the methoxy group in orto (2) instead of para position (4). This allows them to be comparable.

This research is to be intended as a preliminary study and mainly focuses on the phase change transition temperatures, enthalpies of fusion, thermal conductivities, degradation temperatures, densities, toxicities and natural occurrences of the materials in order to draw a first conclusion on their 
suitability as PCMs. Based on the results obtained, further investigations to eventually confirm any specific behaviour observed by the authors will be performed.

Additionally, the manuscript presented here is part of a wider study conducted by the authors aimed at gaining further insight on the thermal behaviour of esters as possible PCM for LHS applications.<smiles>COC(=O)c1ccc2cc(C(=O)OC)ccc2c1</smiles>

2,6-Dimethyl Naphthalenedicarboxylate (2,6-DMNDC)<smiles>O=C(Oc1ccccc1)c1ccccc1</smiles>

Phenyl Benzoate (PHB)<smiles>COC(=O)c1ccco1</smiles>

Methyl-2-Furoate (Me-2-Fu)<smiles>COC(=O)c1ccccc1OC</smiles>

Methyl-2-Methoxybenzoate (Me-2-MeBe)<smiles>COC(=O)c1ccc(C(=O)OC)cc1</smiles>

Dimethyl Terephthalate (DiMeOHTe)<smiles>O=C(OCc1ccccc1)C(=O)OCc1ccccc1</smiles>

Dibenzyl Oxalate (DBO)<smiles>COc1ccc(COC(C)=O)cc1</smiles>

Anisyl Acetate (AnAc)<smiles>O=C(OCc1ccccc1)c1ccccc1</smiles>

Benzyl Benzoate (BEB)

Figure 1. Chemical structures, IUPAC names and abbreviations of the aromatic esters presented in this study.

With the exception of the densities and some melting points, to the best of the authors' knowledge, this is the first time the thermal properties of the compounds have been measured and evaluated, specifically in regards to TES applications and in correlation to their chemical structures.

\section{Materials and Methods}

\subsection{Materials}

All materials were purchased from Sigma Aldrich (St. Louis, MI, USA) and used without any prior purification. In particular, the compounds obtained are listed hereby alongside the abbreviations and 
their degree of purity within brackets: Dibenzyl Oxalate (DBO, 98\%), Dimethyl-2,6-naphthalene dicarboxylate (2,6-DMNDC, 98\%), Anysil acetate (AnAc, $\geq 97 \%$ ), Methyl-2-methoxybenzoate (Me-2-MeBe, 99\%), Benzyl Benzoate (BEB, $\geq 99 \%$ ), Dimethyl terephthalate (DiMeOHTe, $\geq 99 \%$ ), Methyl-2-furoate (Me-2-Fu, $\geq 98 \%$ ), Phenyl benzoate (PHB, 99\%).

\subsection{Characterization}

\subsubsection{Density}

Different procedures were employed to measure the density of aromatic esters based on their melting points, as all the densities were measured in the liquid state. The density of the aromatic esters which are liquid at room temperature were measured as a measure of mass over volume on a microscale MT5 by METTLER TOLEDO (Columbus, OH, USA) with a Gilson (Middleton, WI, USA) PIPETMAN P1000 $1 \mathrm{~mL}$ pipette at room temperature (approx. $25^{\circ} \mathrm{C}$ ). The declared uncertainties of the scale and the pipette are $0.0008 \mathrm{mg}$ and $8 \mu \mathrm{L}$, respectively.

Concerning those aromatic esters of which the $T_{m}$ is above room temperature but $<100{ }^{\circ} \mathrm{C}$, the measurements were performed by first heating the sample at $90^{\circ} \mathrm{C}$, then equilibrating the sample at the chosen temperature for approximately $30 \mathrm{~min}$, and finally measuring the volume and mass with the same procedure mentioned above.

Finally, the densities of the aromatic esters with $T_{m}>100^{\circ} \mathrm{C}$ (namely 2,6-DMNDC and DiMeOHTe) were measured with a $10 \mathrm{~mL}$ graduated cylinder with an uncertainty of $0.1 \mathrm{~mL}$ directly inside an oven by BINDER GmbH (Tuttlingen, DE) at 210 and $155^{\circ} \mathrm{C}$ respectively.

The measurements were repeated three times to ensure accuracy, thus the reported values refer to the averages and relative standard deviations.

\subsubsection{Differential Scanning Calorimetry (DSC)}

The melting and crystallization temperatures $\left(T_{m}\right.$ and $\left.T_{c}\right)$, and enthalpies of fusion $(\Delta H)$ were measured with a DSC 823e and a DSC $3+$ by METTLER TOLEDO (Columbus, OH, USA), both equipped with robotic autosamplers. The DSCs were calibrated with indium standards before the measurements, and the uncertainty of the instruments is declared by the manufacturer as $\pm 0.1 \mathrm{~K}$. All measurements were conducted under a constant flow of nitrogen at a rate of $50 \mathrm{~mL} / \mathrm{min}$, and sample masses were typically between 5 and $10 \mathrm{mg}$.

In order to individuate the phase change transition, a screening measurement was first conducted between $-60{ }^{\circ} \mathrm{C}$ and $200{ }^{\circ} \mathrm{C}$ with a heating rate of $10 \mathrm{~K} / \mathrm{min}$. Afterwards, each aromatic ester was measured in a temperature range around the melting temperature $\left(T_{m}\right)$ from $T_{m}-30{ }^{\circ} \mathrm{C}$ to $T_{m}+30{ }^{\circ} \mathrm{C}$ with the following method: first, one cycle at $10 \mathrm{~K} / \mathrm{min}$ to ensure full homogenization of the sample. Afterwards, three consecutive cycles at $10 \mathrm{~K} / \mathrm{min}$ and three consecutive cycles at $2 \mathrm{~K} / \mathrm{min}$ were performed. To evaluate the data, the first cycle at $10 \mathrm{~K} / \mathrm{min}$ was discarded, and only the data from the consecutive cycles at $10 \mathrm{~K} / \mathrm{min}$ ( 3 cycles) and $2 \mathrm{~K} / \mathrm{min}$ ( 3 cycles) were effectively used. This avoids discrepancies and outliers due to a wrong conditioning of the sample in the first measurements.

The two heating rates selected were chosen both on recommendation by METTLER TOLEDO and based on the study conducted by Castellón et al. [23]. At $10 \mathrm{~K} / \mathrm{min}$, the error on the $\Delta H$ is minimized, while at $2 \mathrm{~K} / \mathrm{min}$ the phase change transition values tend to be more accurate. Therefore, testing at both heating rates allowed for a more precise identification of $T_{m}, T_{c}$ and $\Delta H$.

To ensure statistical relevance and to evaluate the accuracy of the results, each compound was sampled three times and measured with the procedure described above.

As BEB, AnAc and Me-2-MeBe did not show any crystallization until $-60{ }^{\circ} \mathrm{C}$, they were sent to METTLER TOLEDO and measured there with a DSC3+ equipped with FRS-Sensor and liquid nitrogen cooling. In this case, a first cooling screening between room temperature and $-150{ }^{\circ} \mathrm{C}$ at $10 \mathrm{~K} / \mathrm{min}$ followed by a heating at $10 \mathrm{~K} / \mathrm{min}$ back to room temperature, performed to identify the crystallization ranges. Afterwards, the materials were cycled three times at 10 and $2 \mathrm{~K} / \mathrm{min}$ 
with the same procedure used for the other esters, as described above. Due to limited access to METTLER TOLEDO's instrumentation, only one sample of BEB, AnAc and Me-2-MeBe, respectively, was measured.

The melting and crystallization peaks were evaluated by the METTLER TOLEDO STARe software (v. 16.20) through the tangent method, and the enthalpies were calculated by integration of the corresponding peaks with a linear baseline. The degree of supercooling was estimated as the difference between the onset $T_{m}$ and the onset $T_{c}$ measured.

The means for all six cycles at 10 and $2 \mathrm{~K} / \mathrm{min}$ for $T_{m}, T_{c}$ and $\Delta H$ are reported alongside the relative standard deviations. Although the different heating rates have an influence on the shape and range of the melting/crystallization peaks, this is accounted for in the standard deviation. The values reported in the next pages have an overestimated standard deviation due to this reason, thus portraying the worst scenario in terms of phase change transition ranges.

\subsubsection{Thermal Cycling with EasyMax}

Since BEB could be crystallized overnight at $-20^{\circ} \mathrm{C}$ but not in the DSC, it was assumed that this was caused by enhanced supercooling in the DSC due to the small sample size. Therefore, in addition to DSC experiments with liquid nitrogen, BEB was also cycled with the same procedure between -30 and $50^{\circ} \mathrm{C}$ in a METTLER TOLEDO (Columbus, OH, USA) EasyMax 102 unit. The sample size in this case amounted to approximately $5 \mathrm{~mL}$. Due to the absence of a calorimetry unit, the phase change enthalpy could not be evaluated with this method. The temperature was programmed in the METTLER TOLEDO iControl software ${ }^{\mathrm{TM}}$ (v. 5.4), and the data were exported and analyzed with RStudio. The onset $T_{m}$ was estimated with tangent method based on the melting plateau, while the onset $T_{\mathcal{c}}$ was chosen as the first temperature at which the material supercools before reaching constant temperature during the phase change. Similarly to what was done for the DSC data, the degree of supercooling was calculated as the difference between the onset $T_{m}$ and the onset $T_{c}$. To ensure statistical relevance, BEB was sampled and cycled in the EasyMax three times.

\subsubsection{Thermogravimetric Analysis (TGA)}

The samples' degradation temperatures were measured on a TGA STARe 2 system and a TGA/DSC 3+ by METTLER TOLEDO (Columbus, OH, USA) equipped with autosamplers in the temperature range between 25 and $600{ }^{\circ} \mathrm{C}$ with a heating rate of $10 \mathrm{~K} / \mathrm{min}$ and sample masses between 15 and $20 \mathrm{mg}$ as per METTLER TOLEDO and Perkin Elmer's recommendation [24]. The uncertainty of the instrument is reported to be $\pm 0.1 \mu \mathrm{g}$.

Prior to any sequence of measurements, a blank measurement of the empty crucible was performed for baseline subtraction.

To ensure statistical relevance and to evaluate the accuracy of the results, each compound was sampled and measured three times with the procedure described above.

The degradation temperatures and mass losses were calculated via tangent method with the METTLER TOLEDO STARe software (v. 16.20).

The starting degradation temperature $\left(T_{\text {degr onset }}\right)$ was defined as the earliest temperature for which mass losses $\geq 5 \%$ were observed. The end degradation temperature $\left(T_{\text {degr endset }}\right)$ was defined as the earliest temperature for which mass losses of $\geq 99 \%$ were registered.

\subsubsection{Transient Hot Bridge (THB)}

Thermal conductivity measurements were performed using a Thermal Hot Bridge THB100 by LINSEIS GmbH (Selb, DE). The THB100 is equipped with a Thyristor L70/2171 as a power supply and a furnace for measurements at temperatures above room temperature (RT). The uncertainty of the instrument for the thermal conductivity declared by the manufacturer is $0.01 \mathrm{~W} /(\mathrm{m} \cdot \mathrm{K})$. All samples were measured in the liquid state in a $12 \mathrm{~mL}$ passivated alumina sample holder with a Kaptonsensor MFR THB6N $82 \times 42 \mathrm{~mm}$. For those aromatic esters which are in a liquid state at room temperature, 
the analysis was conducted at a constant temperature of $30^{\circ} \mathrm{C}$ in a heated oven. For all other aromatic esters, the temperature in the furnace was fixed at $20^{\circ} \mathrm{C}$ above the melting point $T_{m}$.

To achieve precise results, first the appropriate measuring current $(\mathrm{mA})$ and time (s) have to be selected. Short times have to be used to avoid incurring inflection points in the potential, while the measuring current should be chosen within a range in which the conductivity of the material stays constant [25]. Thus to identify the optimal values, a preliminary test was conducted for all aromatic esters with a time of $55 \mathrm{~s}$ and varying the current from 30 to $70 \mathrm{~mA}$ by steps of $5 \mathrm{~mA}$. Then, the thermal conductivities $(\mathrm{W} /(\mathrm{m} \cdot \mathrm{K}))$ obtained were plotted against the current, and the lowest current at which a constant thermal conductivity was reached was then chosen as measuring current for further experiments. Afterward, the conductivity of the sample was measured over time with the selected current between 30 and $75 \mathrm{~s}$ by steps of $10 \mathrm{~s}$. For each measuring time selected, the instrument retrieves three measurements of the thermal conductivity and calculates the mean.

For each aromatic ester, three different samples were prepared and analyzed according to the procedure explained above. The values reported in the next sections represent the average thermal conductivity for three samples with the relative standard deviations.

All data were retrieved and analyzed through the LINSEIS Software Platinum.

\section{Results and Discussion}

In the next chapters, the thermal properties of aromatic esters are evaluated in terms of density $(\rho)$, phase change transitions (onset melting $T_{m}$ and crystallization $T_{c}$ temperatures), degree of supercooling, phase change enthalpies $(\Delta H)$, onset and endset thermal degradation $\left(T_{\text {degr onset }}, T_{\text {degr endset }}\right)$ and thermal conductivity $(\lambda)$. Based on their values and reliability, the aromatic esters are assessed as possible PCMs for LHS applications. Their safety and toxicity as reported from sources in the literature is considered as well.

\subsection{Density}

Table 1 summarizes the densities $\rho(\mathrm{g} / \mathrm{mL})$ of the aromatics in the liquid state measured with the methods described in the apposite section. For each compound, the temperatures $\left({ }^{\circ} \mathrm{C}\right)$ at which the measurements were performed are indicated. The values reported represent the average values between three measurements and indicated alongside are their standard deviations. In order to confirm the validity of the results obtained, the densities of the compounds reported in the literature (Sigma Aldrich) are indicated alongside the measuring temperature. Missing densities in the literature are reported as Not Available (NA).

Table 1. Summary of the densities $\rho(\mathrm{g} / \mathrm{mL})$ measured for the aromatic esters presented. As the measurements were conducted with the materials in the liquid state, the measurement temperatures vary from sample to sample. For each ester, the chemical structure and carbon numbers are indicated alongside the temperature $\left({ }^{\circ} \mathrm{C}\right)$ at which the measurements were performed. In this case, RT stands for "Room Temperature", which amounts to approximately $25^{\circ} \mathrm{C}$. If present, density values from the literature (lit.) (Sigma Aldrich) are reported alongside the measuring temperature. The missing values are indicated as Not Available (NA). All the $\rho$ of the aromatic esters are higher than 1 , which gives rise to higher volumetric $\Delta H[\mathrm{~J} / \mathrm{mL}]$.

\begin{tabular}{cccccc}
\hline Ester & Structure & Carbon Number & Measuring $\mathbf{T}\left({ }^{\circ} \mathrm{C}\right)$ & $\rho$ [g/mL $]$ & $\rho$ lit. $[\mathrm{g} / \mathrm{mL}]$ \\
\hline DBO & $\left(\mathrm{CO}_{2} \mathrm{CH}_{2} \mathrm{C}_{6} \mathrm{H}_{5}\right)_{2}$ & 16 & 90 & $1.22 \pm 0.01$ & NA \\
2,6-DMNDC & $\mathrm{C}_{10} \mathrm{H}_{6}\left(\mathrm{CO}_{2} \mathrm{CH}_{3}\right)_{2}$ & 14 & 210 & $1.09 \pm 0.01$ & NA \\
BEB & $\mathrm{C}_{6} \mathrm{H}_{5} \mathrm{COOCH}_{2} \mathrm{COCH}_{5}$ & 14 & $\mathrm{RT}$ & $1.12 \pm<0.01$ & $1.12\left(20^{\circ} \mathrm{C}\right)$ \\
PHB & $\mathrm{C}_{6} \mathrm{H}_{5} \mathrm{CO}_{2} \mathrm{C}_{6} \mathrm{H}_{5}$ & 13 & 90 & $1.19 \pm 0.01$ & NA \\
DiMeOHTe & $\mathrm{C}_{6} \mathrm{H}_{4}-1,4-\left(\mathrm{CO}_{2} \mathrm{CH}_{3}\right)_{2}$ & 10 & 155 & $1.09 \pm 0.01$ & NA \\
AnAc & $\mathrm{CH}_{3} \mathrm{CO}_{2} \mathrm{CH}_{2} \mathrm{C}_{6} \mathrm{H}_{4}-4-\left(\mathrm{OCH}_{3}\right)$ & 9 & $\mathrm{RT}$ & $1.11 \pm<0.01$ & $1.11\left(25^{\circ} \mathrm{C}\right)$ \\
$\mathrm{Me}-2-\mathrm{MeBe}$ & $\mathrm{CH}_{3} \mathrm{OC}_{6} \mathrm{H}_{4} \mathrm{CO}_{2} \mathrm{CH}_{3}$ & 9 & $\mathrm{RT}$ & $1.16 \pm 0.01$ & $1.16\left(25^{\circ} \mathrm{C}\right)$ \\
Me-2-Fu & $\mathrm{C}_{6} \mathrm{H}_{6} \mathrm{O}_{3}$ & 6 & RT & $1.18 \pm 0.01$ & $1.18\left(25^{\circ} \mathrm{C}\right)$ \\
\hline
\end{tabular}


Unlike most other esters and organic materials [26], the aromatic esters all present $\rho>1 \mathrm{~g} / \mathrm{mL}$, between $1.09 \mathrm{~g} / \mathrm{mL}$ for 2,6-DMNDC and DiMeOHTe, and $1.22 \mathrm{~g} / \mathrm{mL}$ for DBO. This represents a great advantage for LHS applications, since it increases the volumetric storage density.

In general, no clear trend correlating $\rho$ to the chemical structures or carbon numbers can be noticed. However, should all aromatic esters be characterized by $\rho>1 \mathrm{~g} / \mathrm{mL}$, they would be interesting candidates due to high volumetric densities over other classes of esters with $\rho<1 \mathrm{~g} / \mathrm{mL}$. This would need to be confirmed with further studies on a bigger number of aromatic esters.

\subsection{Phase Change Temperatures}

Table 2 reports the average values obtained with relative standard deviations for $T_{m}, T_{c}, \Delta H$, $T_{\text {degr onset }}$ and $T_{\text {degr endset }}$. Additionally, the degree of supercooling (intended as onset $T_{m}$-onset $T_{c}$ ), the volumetric enthalpy $(\mathrm{J} / \mathrm{mL})$ and the molar one $(\mathrm{kJ} / \mathrm{mol})$ are calculated for each compound. The molar enthalpies of fusion are calculated as the product of the $\Delta H$ with the MW. The volumetric enthalpies of fusion are calculated as the product of the $\Delta H$ with the density $\rho$.

For comparison, Table 3 shows the known literature values for the $T_{m}$ of some of the aromatic esters. No information was found on the $\Delta H, T_{\text {degr onset }}$ and $T_{\text {degr endset }}$, and therefore it is not presented in the table.

In general, aromatic esters present onset $T_{m}$ in a wide range of temperatures from a minimum of approximately $-16{ }^{\circ} \mathrm{C}$ for AnAc to a maximum of $190^{\circ} \mathrm{C}$ for 2,6-DMNDC. Unlike fatty esters [11,12], aromatic esters are characterized by a high degree of supercooling for samples sizes in the range of $\mathrm{mg}$. While the supercooling tends to be enhanced in small samples, the difference with paraffins or fatty esters is still noticeable. Only DiMeOHTe and 2,6-DMNDC present lower supercooling $\left(9\right.$ and $13^{\circ} \mathrm{C}$, respectively), comparable to that of other esters.

As AnAc, BEB and Me-2-MeBe did not crystallize until the lower limit of the DSC $\left(-60{ }^{\circ} \mathrm{C}\right)$, they were analyzed by METTLER TOLEDO in a DSC equipped with liquid nitrogen (lower limit $-150{ }^{\circ} \mathrm{C}$ ) (Appendix A). This allowed estimation of the phase change transition temperatures. Both AnAc and BEB did not seem to crystallize, as can be seen by the lack of peaks in the cooling curves. The presence of a glass transition around $-75--80^{\circ} \mathrm{C}$ suggests the molecules arrange themselves in an amorphous glass-like structure during a cold crystallization. Only in the case of AnAc, a cold crystallization took place in presence of liquid nitrogen, which allowed estimation of the $T_{m}$.

As AnAc could not be crystallized in the DSC, the $T_{c}$ could not be determined.

In the case of Me-2-MeBe, no crystallization was observed until $-150{ }^{\circ} \mathrm{C}$, therefore $T_{c}, T_{m}$ and $\Delta H$ could not be measured. The data are indicated as Not Available (NA) in Table 2.

Both AnAc and BEB show several solid-solid transformations (exothermic peaks) during the heating step, which is indicative of polymorphism. No information on the crystalline phases or the general polymorphic behaviour of these compounds have been found in the literature. Due to the overlapping peaks and the polymorphism, the $\Delta H$ of AnAc and BEB could not be calculated and is reported as NA in Table 2.

In order to estimate BEB's $T_{c}$, consecutive heating/cooling cycles in a METTLER TOLEDO's EasyMax 102 cycling unit were performed (Appendix B). As the sample size amounts to approximately $5 \mathrm{~g}$, the degree of supercooling observed was less prominent than in the DSC and it allowed BEB to properly crystallize. Nevertheless, similarly to the other aromatic esters, BEB is characterized by a much higher degree of supercooling compared to other esters' subclasses. The polymorphism of BEB could also be observed and confirmed in the EasyMax experiments by the presence of multiple plateaus during melting and crystallization. 
Table 2. Summary of thermal properties of the commercial aromatic esters investigated. $T_{m}$ and $T_{\mathcal{c}}$ stand for the onset melting and crystallization temperature, respectively, $\Delta H$ stands for the enthalpy of fusion, and $T_{\text {degr onset }}$ and $T_{\text {degr endset }}$ represent the starting and ending degradation temperatures. The molecular weight is abbreviated as MW $(\mathrm{g} / \mathrm{mol})$. The aromatic esters are ordered according to decreasing carbon number. The $T_{m}, T_{\mathcal{c}}$ and $\Delta H$ values reported are the average value of three measurements for each compound conducted with six consecutive heating/cooling cycles at 10 and $2 \mathrm{~K} / \mathrm{min}$, and are indicated alongside their standard deviations. In the case of experiments run with METTLER TOLEDO's DSC with liquid nitrogen (AnAc, BEB, Me-2-MeBe), only one sample per compound was measured. The average calculated from these experiments is indicated in bold ${ }^{* *}$ and might not be fully representative of the compound's properties. BEB was cycled both in a DSC equipped with liquid nitrogen and in a EasyMax cycling unit. The $T_{c}$ was calculated from the EasyMax experiment $\left.{ }^{*}\right)$, while the $T_{m}$ from the DSC one $\left.{ }^{* *}\right)$. Missing data are indicated as Not Available (NA).

\begin{tabular}{|c|c|c|c|c|c|c|c|c|c|c|c|}
\hline Ester & Structure & Carbon Number & MW [g/mol] & $T_{c}\left[\right.$ Onset, $\left.{ }^{\circ} \mathrm{C}\right]$ & $T_{m}\left[\right.$ Onset, $\left.{ }^{\circ} \mathrm{C}\right]$ & Supercooling $\left[{ }^{\circ} \mathrm{C}\right]$ & $\Delta H[\mathrm{~J} / \mathrm{g}]$ & $\Delta H[\mathrm{~kJ} / \mathrm{mol}]$ & Volumetric $\Delta H[\mathrm{~J} / \mathrm{mL}]$ & $T_{\text {degr onset }}\left[{ }^{\circ} \mathrm{C}\right]$ & $T_{\text {degr endset }}\left[{ }^{\circ} \mathrm{C}\right]$ \\
\hline DBO & $\left(\mathrm{CO}_{2} \mathrm{CH}_{2} \mathrm{C}_{6} \mathrm{H}_{5}\right)_{2}$ & 16 & 270.3 & $50.8 \pm 10.6$ & $78.5 \pm 0.3$ & $27.7 \pm 10.4$ & $131.0 \pm 7.0$ & $35.4 \pm 1.9$ & $159.8 \pm 8.6$ & $175 \pm 5$ & $530 \pm 15$ \\
\hline 2,6-DMNDC & $\mathrm{C}_{10} \mathrm{H}_{6}\left(\mathrm{CO}_{2} \mathrm{CH}_{3}\right)_{2}$ & 14 & 244.2 & $177.0 \pm 1.2$ & $190.2 \pm 0.8$ & $13.2 \pm 1.3$ & $158.4 \pm 3.9$ & $38.7 \pm 0.9$ & $172.7 \pm 4.2$ & $220 \pm 13$ & $325 \pm 10$ \\
\hline BEB & $\mathrm{C}_{6} \mathrm{H}_{5} \mathrm{COOCH}_{2} \mathrm{C}_{6} \mathrm{H}_{5}$ & 14 & 212.2 & $-19.1 * \pm 1.6$ & $18.1 * * \pm 1.2$ & $37.2 \pm 2.1$ & NA & NA & NA & $148 \pm 3$ & $282 \pm 13$ \\
\hline PHB & $\mathrm{C}_{6} \mathrm{H}_{5} \mathrm{CO}_{2} \mathrm{C}_{6} \mathrm{H}_{5}$ & 13 & 198.2 & $19.0 \pm 1.4$ & $68.3 \pm 0.1$ & $49.3 \pm 1.3$ & $102.0 \pm 4.5$ & $20.2 \pm 0.9$ & $121.4 \pm 5.3$ & $143 \pm 13$ & $273 \pm 10$ \\
\hline DiMeOHTe & $\mathrm{C}_{6} \mathrm{H}_{4}-1,4-\left(\mathrm{CO}_{2} \mathrm{CH}_{3}\right)_{2}$ & 10 & 194.2 & $131.4 \pm 1.9$ & $140.2 \pm 0.1$ & $8.7 \pm 1.9$ & $154.6 \pm 1.5$ & $30.0 \pm 0.3$ & $168.5 \pm 1.6$ & $150 \pm 5$ & $244 \pm 5$ \\
\hline AnAc & $\mathrm{CH}_{3} \mathrm{CO}_{2} \mathrm{CH}_{2} \mathrm{C}_{6} \mathrm{H}_{4}-4-\left(\mathrm{OCH}_{3}\right)$ & 9 & 180.2 & NA & $-15.7 * * \pm 0.5$ & $\mathrm{NA}$ & NA & $\mathrm{NA}$ & NA & $123 \pm 4$ & $237 \pm 6$ \\
\hline Me-2-MeBe & $\mathrm{CH}_{3} \mathrm{OC}_{6} \mathrm{H}_{4} \mathrm{CO}_{2} \mathrm{CH}_{3}$ & 9 & 166.2 & NA & NA & NA & NA & NA & NA & $122 \pm 3$ & $217 \pm 8$ \\
\hline $\mathrm{Me}-2-\mathrm{Fu}$ & $\mathrm{C}_{6} \mathrm{H}_{6} \mathrm{O}_{3}$ & 6 & 126.1 & $-46.9 \pm 1.3$ & $-3.8 \pm 0.3$ & $43.1 \pm 1.5$ & $97.7 \pm 5.9$ & $12.3 \pm 0.7$ & $115.2 \pm 7.0$ & $67 \pm 21$ & $213 \pm 49$ \\
\hline
\end{tabular}

* Average value from EasyMax measurements; ** Average value from DSC with liquid nitrogen measurements.

Table 3. Summary of the literature values on the phase change temperatures of the commercial aromatic esters investigated. Missing data are indicated as Not Available (NA). No information on the enthalpies or degradation temperatures have been found, therefore it is not reported.

\begin{tabular}{ccccc}
\hline Ester & Structure & Carbon Number & MW [g/mol] & $\boldsymbol{T}_{\boldsymbol{m}}$ lit. (Chemical Suppliers) \\
\hline DBO & $\left(\mathrm{CO}_{2} \mathrm{CH}_{2} \mathrm{C}_{6} \mathrm{H}_{5}\right)_{2}$ & 16 & 270.3 & $75-78$ \\
2,6-DMNDC & $\mathrm{C}_{10} \mathrm{H}_{6}\left(\mathrm{CO}_{2} \mathrm{CH}_{3}\right)_{2}$ & 14 & 244.2 & $187-193$ \\
BEB & $\mathrm{C}_{6} \mathrm{H}_{5} \mathrm{COOCH}_{2} \mathrm{C}_{6} \mathrm{H}_{5}$ & 14 & 212.2 & 18 \\
PHB & $\mathrm{C}_{6} \mathrm{H}_{5} \mathrm{CO}_{2} \mathrm{C}_{6} \mathrm{H}_{5}$ & 13 & 198.2 & 71 \\
DiMeOHTe & $\mathrm{C}_{6} \mathrm{H}_{4}-1,4-\left(\mathrm{CO}_{2} \mathrm{CH}_{3}\right)_{2}$ & 10 & 194.2 & 142 \\
AnAc & $\mathrm{CH}_{3} \mathrm{CO}_{2} \mathrm{CH}_{2} \mathrm{C}_{6} \mathrm{H}_{4}-4-\left(\mathrm{OCH}_{3}\right)$ & 9 & 180.2 & NA \\
Me-2-MeBe & $\mathrm{CH}_{3} \mathrm{OC}_{6} \mathrm{H}_{4} \mathrm{CO}_{2} \mathrm{CH}_{3}$ & 9 & 166.2 & NA \\
Me-2-Fu & $\mathrm{C}_{6} \mathrm{H}_{6} \mathrm{O}_{3}$ & 6 & 126.1 & NA \\
\hline
\end{tabular}


Figure 2 shows the onset $T_{c}$ and $T_{m}$ of the aromatic esters plotted against their carbon numbers (Carbon Number). Each point represents the average value of three measurements conducted in the DSC with six consecutive heating/cooling cycles at 10 and $2 \mathrm{~K} / \mathrm{min}$, and the error bars represent the standard deviations. Due to the impossibility of determining the temperatures, Me-2-MeBe's $T_{m}$ and $T_{\mathcal{c}}$, and AnAc's $T_{\mathcal{c}}$ are not reported in the graph.

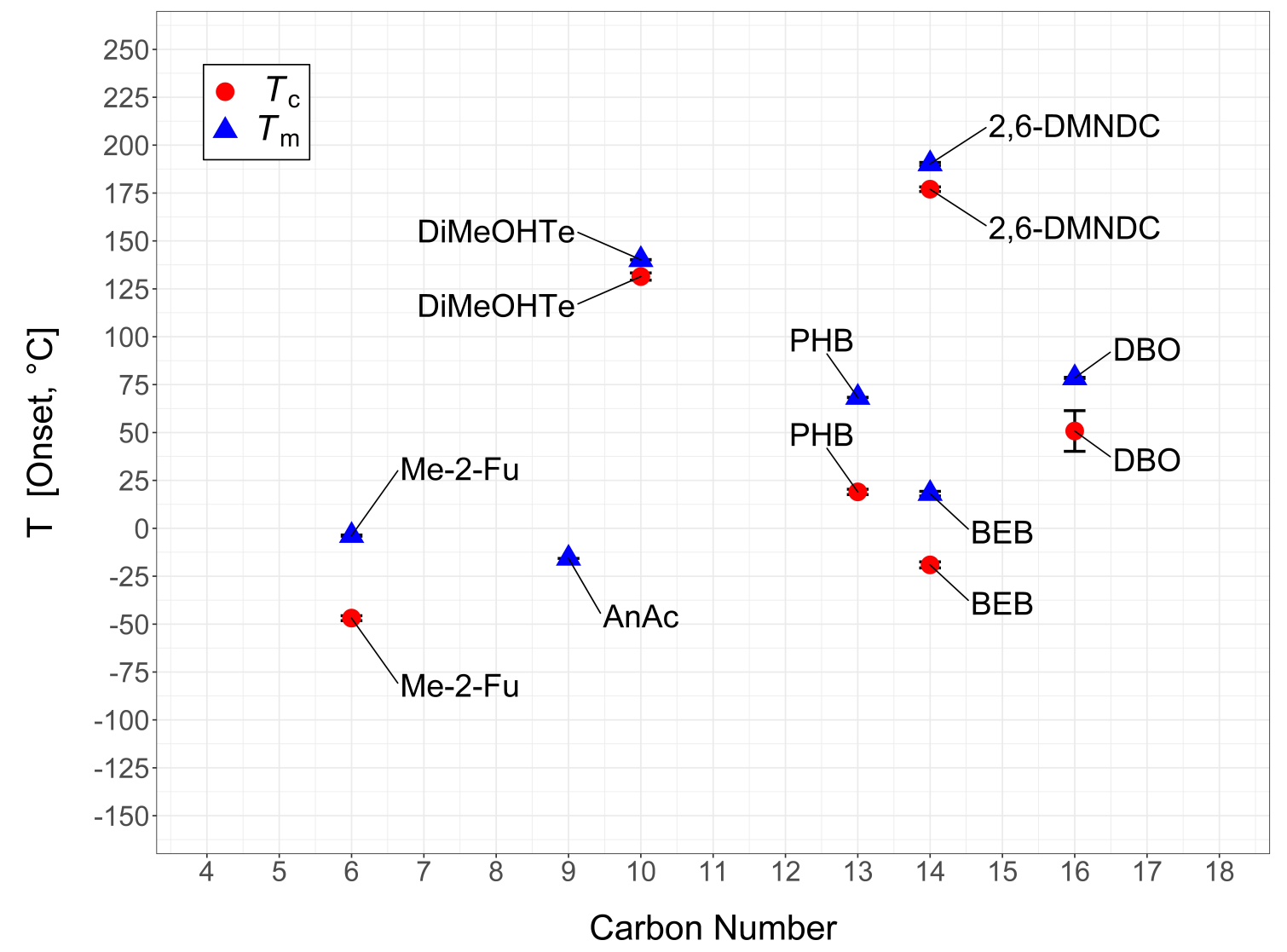

Figure 2. Scatter plot of the average onset melting points $\left(T_{m}\right.$, red triangle) and crystallization points ( $T_{c}$, blue circle) plotted against the carbon numbers (Carbon Number). The aromatic esters for which the phase change temperatures could not be determined do not appear in the plot. The error bars represent the standard deviation between the melting point of three repeated measurements for each compound, with the exception of AnAc and of BEB's $T_{m}$. In general a wide range of temperature is observed, with a maximum $T_{m}$ of $190{ }^{\circ} \mathrm{C}$ for 2,6-DMNDC and a minimum $T_{m}$ of $-16{ }^{\circ} \mathrm{C}$ for AnAc. A high degree of supercooling is visible for all samples except DiMeOHTe and 2,6-DMNDC.

Generally, no clear trend correlating the carbon number to the $T_{m}$ of the aromatic esters is observed. However, what appear as structural influences over the $T_{m}$ can be noticed.

$\mathrm{PHB}, \mathrm{BEB}$ and DBO present two aromatic rings at the extremes of the carboxylic group in the middle of the molecule. On the opposite, DiMeOHTe, AnAc and 2,6-DMNDC have an aromatic moiety in the middle of the molecule, with aliphatic substituents on the extremes. Me-2-Fu and Me-2-MeBe present aliphatic substituents only on one side of the molecule, therefore are rather asymmetrical.

Due to the rotational freedom of carboxylic groups, as reported in the literature [27], it can be assumed that the presence of an aromatic ring between two carboxylic groups generates more stable crystalline structures compared to compounds with the aromatic groups as end groups. This would explain the higher degree of supercooling observed for $\mathrm{PHB}\left(49.3^{\circ} \mathrm{C}\right)$, BEB $\left(37.2^{\circ} \mathrm{C}\right)$ and $\mathrm{DBO}\left(27.7^{\circ} \mathrm{C}\right)$. This also explains the lower $T_{m}$ of PHB, DBO and BEB compared to other aromatics with equal or lower carbon number. For example, although BEB and 2,6-DMNDC both have carbon number 14, 2,6-DMNDC $\left(T_{m} 190.2{ }^{\circ} \mathrm{C}\right)$ is characterized by $T_{m}$ higher than BEB $\left(T_{m} 18.1^{\circ} \mathrm{C}\right)$ of $172.1^{\circ} \mathrm{C}$. 
As previously mentioned, DiMeOHTe is both an aromatic ester, due to the presence of the aromatic ring in the terephthalic group, and a diester. Compared to other methyl diesters, such as for example dimethyl oxalate ( $\mathrm{DiMeOHOx}, \mathrm{C}_{4}$ ), dimethyl succinate (DiMeOHSu, $\mathrm{C}_{6}$ ), dimethyl suberate (DiMeOHSub, $\mathrm{C}_{10}$ ), and dimethyl sebacate (DiMeOHSe, $\mathrm{C}_{12}$ ) [17], DiMeOHTe $\left(\mathrm{C}_{10}\right)$ presents a much higher $T_{m}$ of $140.2{ }^{\circ} \mathrm{C}$, while the other compounds melt at $46.0,10.1,-16.2$ and $23.3^{\circ} \mathrm{C}$ respectively. As can be observed, DiMeOHTe has a similar, or even the same, carbon number as the diesters mentioned above. Therefore, the presence of the aromatic ring could be the cause behind the increase in $T_{m}$. This is thought to be due to the higher stability of aromatic systems given from the delocalized electron density and $\pi-\pi$ stacking, which creates tightly packed crystalline structures [28]. This also appears to be true for 2,6-DMNDC, which is a di-aromatic ester with carbon number four units above that of DiMeOHTe.

$\mathrm{DBO}$ is an aromatic ester of oxalic acid and can be compared to DiMeOHOx regarding the chemical structure, where the only difference is the presence of two benzyl groups instead of two methyl groups as substituent. DBO melts at $78.5^{\circ} \mathrm{C}$, therefore an increase in the $T_{m}$ due to the presence of the aromatic rings is observed as well. However, DBO possesses a higher carbon number $\left(\mathrm{C}_{16}\right)$ than DiMeOHTe $\left(C_{10}\right)$, but still a lower $T_{m}$ and a higher degree of supercooling too. This could be assumed to be due to the presence of the aromatic groups as end groups, rather than in the middle of the molecule such as for DiMeOHTe. The end groups have higher rotational freedom, which creates disruptions in the crystalline lattice, while it does not when the aromatic ring is in the middle of the molecule.

Despite having a difference of only one additional carbon in its structure, $\mathrm{PHB}\left(T_{m} 68.3^{\circ} \mathrm{C}\right)$ melts at a much higher temperature than BEB $\left(T_{m} 18.1^{\circ} \mathrm{C}\right)$. Therefore, the presence of one additional carbon between one of the aromatic substituent at the extremes, and the carboxylic group in the middle of the molecule, would seem to lower the $T_{m}$ considerably. This would supposedly be due to a higher degree of asymmetry as well.

Although DBO $\left(\mathrm{C}_{16}\right)$ has a higher carbon number than PHB $\left(\mathrm{C}_{13}\right)$ and would be expected to present higher $T_{m}$, it melts at almost the same $T_{m}\left(78.5^{\circ} \mathrm{C}\right)$ as $\mathrm{PHB}\left(T_{m} 68.3^{\circ} \mathrm{C}\right)$. The two molecules have almost identical structure, but DBO presents two additional carbons between the aromatic and the ester groups. Although the difference in $T_{m}$ is not as pronounced as in the case of PHB and BEB, the additional carbons are suspected to hinder the raise in $T_{m}$ and cause lower rigidity in the crystalline structure.

However, it is important to mention that in order to confirm the influence of the structural features described above on the melting points of aromatic esters, further studies on a bigger number of samples would be required.

\subsection{Phase Change Enthalpies}

In terms of enthalpies of fusion $\Delta H(\mathrm{~J} / \mathrm{g})$, the aromatic esters present low to medium values between a minimum of $97.7 \mathrm{~J} / \mathrm{g}$ for Me-2-Fu, and a maximum of 158.4 J/g for 2,6-DMNDC. Figure 3 shows the $\Delta H$ measured plotted against the carbon number (Carbon Number). Similarly to what was done for the phase change temperatures, each point represents the average value of three measurements conducted in the DSC with six consecutive heating/cooling cycles at 10 and $2 \mathrm{~K} / \mathrm{min}$, and the error bars represent the standard deviations. Since BEB, AnAc and Me-2-MeBe did not form stable crystalline structures at $-150{ }^{\circ} \mathrm{C}$ and showed polymorphism, their $\Delta H$ could not be determined and are not presented in the graph.

An increase in $\Delta H$ with carbon number for Me-2-Fu, DiMeOHTe and 2,6-DMNDC is noticed, while $\mathrm{PHB}$ and $\mathrm{DBO}$ show lower values despite a higher carbon number. This might be an indication of the influence on the chemical structure on $\Delta H$ as well, where aromatic substituents at the extreme of the molecule would cause disruptions in the crystal lattice and an ability to absorb and release lower thermal energy during the phase change due to higher instability. This effect is also visible when considering the molar enthalpies of fusion $\Delta H /(\mathrm{kJ} / \mathrm{mol})$. Here as well, $\Delta H$ seems to be increasing with increasing carbon number, with the exception of PHB and DBO. Nevertheless, in order to draw 
stronger conclusions on possible trends correlating the chemical structures to $\Delta H$, further studies are required.

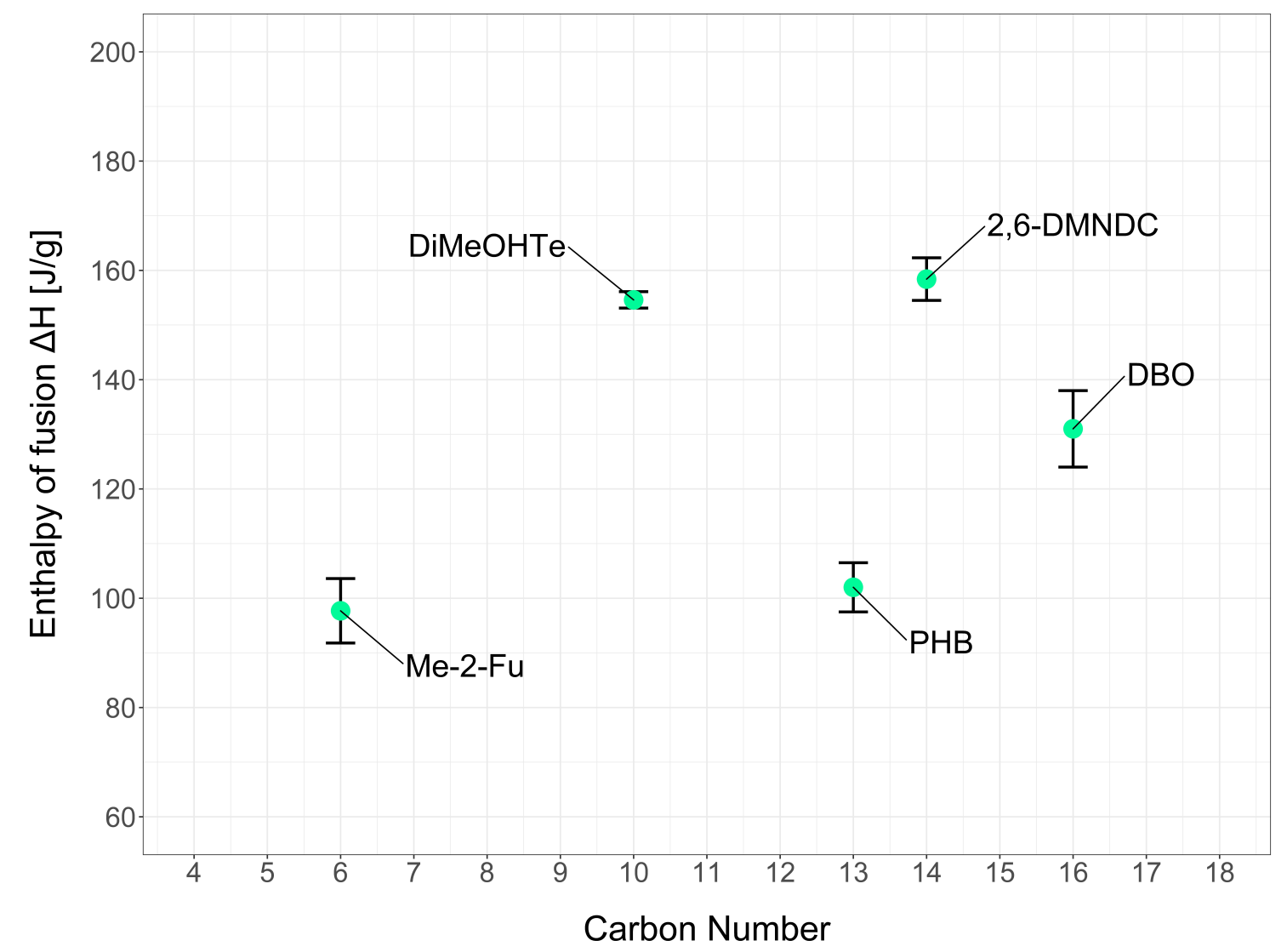

Figure 3. Scatter plot of the average enthalpies of fusion $(\Delta H$, green circle) plotted against the carbon numbers (Carbon Number). The error bars represent the standard deviation between the means of three measurements for each compound. The aromatic esters for which the phase change temperatures could not be determined do not appear in the plot. The $\Delta H$ of aromatics esters are low to medium and reach maximum values of $158.4 \mathrm{~J} / \mathrm{g}$ for 2,6-DMNDC while a minimum of $97.7 \mathrm{~J} / \mathrm{g}$ is measured for $\mathrm{Me}-2-\mathrm{Fu}$. The $\Delta H$ seemingly increases for increasing Carbon $\mathrm{Nr}$, with the exception of PHB and DBO.

Generally, gravimetric $\Delta H(\mathrm{~J} / \mathrm{g})$ below $150 \mathrm{~J} / \mathrm{g}$ are considered not interesting for LHS applications [29]. However, since aromatic esters present densities above $1 \mathrm{~g} / \mathrm{mL}$, the volumetric enthalpy $\Delta \mathrm{H}(\mathrm{J} / \mathrm{mL})$ is higher compared to that of other organic PCMs, which normally are characterized by $\rho$ lower than $1 \mathrm{~g} / \mathrm{mL}$. Therefore, based on the gravimetric and volumetric $\Delta H \mathrm{~J} / \mathrm{g}$ and $\Delta H \mathrm{~J} / \mathrm{mL}$, DiMeOHTe and 2,6-DMNDC represent interesting candidates for high temperature LHS applications.

\subsection{Degradation Temperatures}

Figure 4 shows the onset $\left(T_{\text {degr onset }}\right.$, blue) and endset degradation temperatures $\left(T_{\text {degr endset }}\right.$, red $)$ for all aromatic esters ordered for increasing carbon number. The temperatures are the mean values of three measurements and the error bars are the standard deviations. All the TGA curves of the aromatic esters studies are reported in Appendix $C$.

The aromatic esters show $\left(T_{\text {degr onset }}\right)$ ranging from $67(\mathrm{Me}-2-\mathrm{Fu})$ to $220^{\circ} \mathrm{C}(2,6-\mathrm{DMNDC})$, while the ( $\left.T_{\text {degr endset }}\right)$ extend from $213(\mathrm{Me}-2-\mathrm{Fu})$ to $530^{\circ} \mathrm{C}(\mathrm{DBO})$.

While a linear trend correlating the degradation temperatures to the carbon numbers cannot be observed, a few other considerations can be madee. 


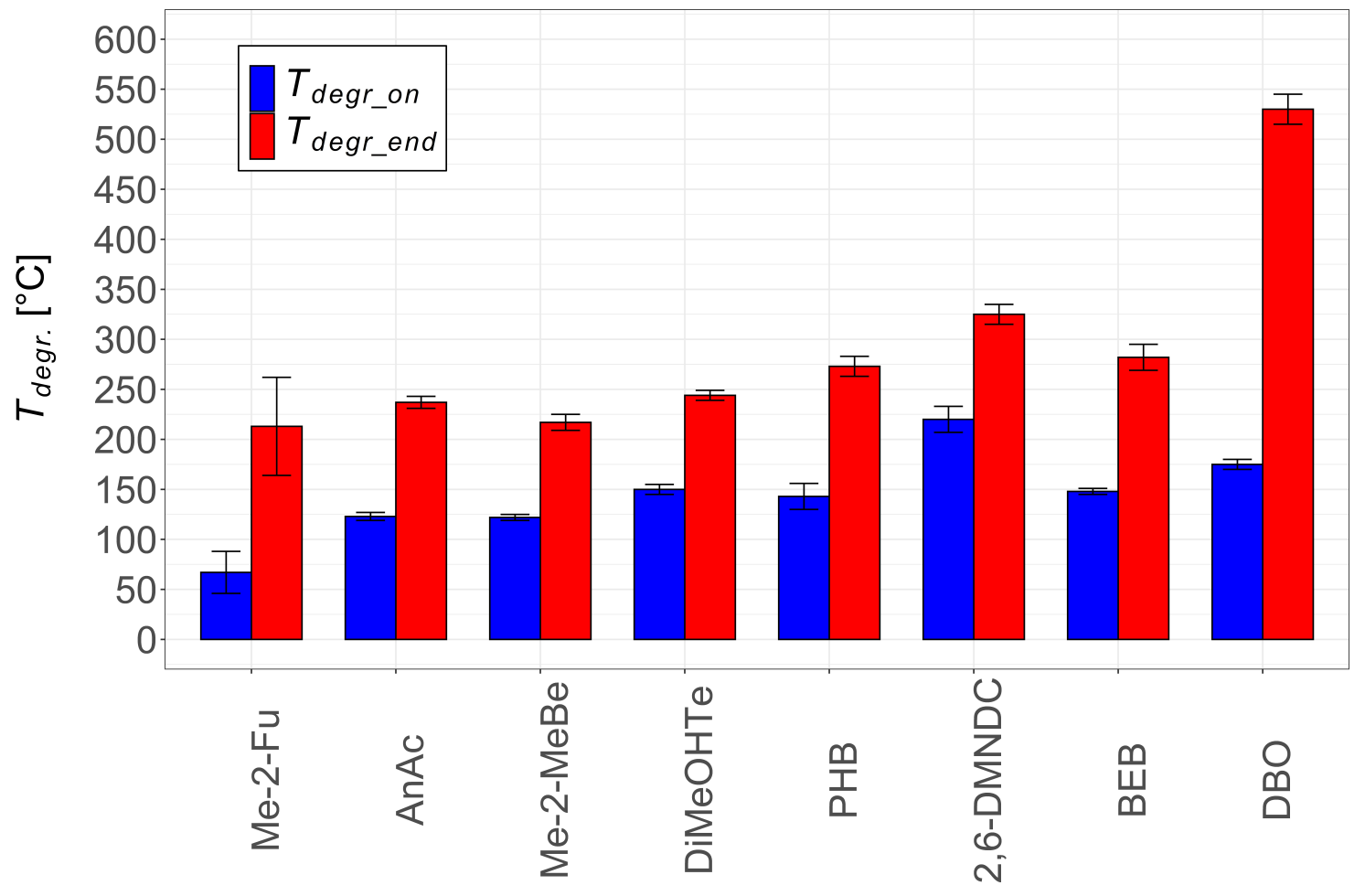

Aromatic Esters

Figure 4. Barplot showing the onset degradation temperature ( $T_{\text {degr }}$ onset, blue bar) and endset degradation temperature $\left(T_{\text {degr }}\right.$ endset, red bar) of the aromatic esters presented. The aromatic esters are ordered according to increasing carbon number. A trend correlating the degradation temperatures to the carbon number seems to arise, with the exception of BEB, which undergoes thermal degradation at lower temperatures.

The aromatic esters with just one aromatic ring (Me-2-Fu, AnAc, Me-2-MeBe, DiMeOHTe) undergo thermal degradation earlier than those with two aromatic rings (PHB, 2,6-DMNDC, BEB, DBO). This is thought to be due to the increased $\pi-\pi$ stacking in structures with two aromatic rings, which raises the overall stability of the materials. Me-2-Fu is the least stable ester amongst those studied, and it is also, interestingly, the only one characterized by a single five-carbon aromatic ring. While additional studies would be needed, this could indicate a lower stability of five-membered rings compared to six-membered ones.

Although PHB, BEB and DBO possess aromatic rings with rotational freedom at the end of the molecule, their overall stability to high temperatures seems not to be impacted.

Despite 2,6-DMNDC and BEB presenting the same carbon number, 2,6-DMNDC is characterized by considerably higher $T_{\text {degr }}$ onset and $T_{\text {degr }}$ endset. This could be due to both 2,6-DMNDC's higher molecular weight, which means a lower volatility, and the presence of aromatic rings in the middle of 2,6-DMNDC's chemical structure.

DBO presents the highest $T_{\text {degr }}$ endset together with the highest molecular weight. This could once again be a consequence of the lower volatility and the increased energy needed to break the bonds. Additionally, DBO is the only aromatic compound to present a two-step degradation, as seen in Appendix C. Benzyl oxalates are known to undergo radicalization to give rise to dibenzyl and other alkylic by-products during pyrolysis [30]. This would explain the two-step degradation seen in the TGA curve. Nevertheless, a more careful evaluation of the degradation mechanism is needed to draw conclusions.

All the aromatics esters start degrading at temperatures well above their $T_{m}$. However, this is not true for DiMeOHTe and 2,6-DMNDC, which present $T_{\text {degr }}$ onset close to their $T_{m}$. This can eventually 
lead to the risk of the ester deteriorating upon usage in a LHS setup. Therefore, this constitutes a limitation to the applicability of these aromatic esters.

\subsection{Thermal Conductivity}

Although the thermal conductivity $(\lambda)$ of the material represents an important parameter to evaluate its suitability as PCM, almost no data were found on the thermal conductivities of esters and of PCMs in general.

Table 4 summarizes the thermal conductivities of the aromatics measured with the THB method. For each compound, the temperature $\left({ }^{\circ} \mathrm{C}\right)$ and current $(I(\mathrm{~mA}))$ at which the measurements were performed are indicated. The values reported represent the average values between three measurements and are reported alongside their standard deviations.

As 2,6-DMNDC's $T_{m}$ exceeds the maximum operational temperature of the THB sensor of $200{ }^{\circ} \mathrm{C}$, its thermal conductivity in the liquid state could not be measured.

Concerning DiMeOHTe, no stable signal in the measurements could be obtained, which did not allow the instrument to correctly calculate its thermal conductivities. This could be due to additional phenomena occurring at such high temperatures, such as an increased convection, which distrupts the calculations made by the software [25]. Additionally, DiMeOHTe showed a high volatility and undergoes $T_{\text {degr onset }}$ as such temperatures, which could have been a cause of the disturbances in the signal as well. Therefore, no data are available for 2,6-DMNDC and DiMeOHTe, and this is reported in Table 4 as NA (Not Available).

As can be observed, the aromatic esters present $\lambda$ values between 0.159 and $0.204 \mathrm{~W} /(\mathrm{m} \cdot \mathrm{K})$, which is in a similar range to what is observed for other organic materials.

Generally, salt hydrates are characterized by $\lambda \leq 0.6 \mathrm{~W} /(\mathrm{m} \cdot \mathrm{K})$, while paraffins and other organics usually show values $\leq 0.2 \mathrm{~W} /(\mathrm{m} \cdot \mathrm{K})[5,31]$.

Table 4. Summary of the thermal conductivities $\lambda(\mathrm{W} /(\mathrm{m} \cdot \mathrm{K}))$ measured for the aromatic esters presented. For each ester, the chemical structure and carbon numbers are indicated alongside the current $I(\mathrm{~mA})$ and temperature $\mathrm{T}\left({ }^{\circ} \mathrm{C}\right)$ at which the measurements were performed. The $\lambda$ of the aromatic esters for which the measurement could not be performed are indicated as Not Available (NA). No significant trends could be observed, and, in general, the $\lambda$ are found to be in the same range as other organic compounds, such as paraffins.

\begin{tabular}{cccccc}
\hline Ester & Structure & Carbon Number & $\boldsymbol{I}[\mathbf{m A}]$ & Measuring $\mathbf{T}\left[{ }^{\circ} \mathrm{C}\right]$ & $\lambda[\mathbf{W} /(\mathbf{m} \cdot \mathbf{K})]$ \\
\hline DBO & $\left(\mathrm{CO}_{2} \mathrm{CH}_{2} \mathrm{C}_{6} \mathrm{H}_{5}\right)_{2}$ & 16 & 50 & 100 & $0.16 \pm 0.01$ \\
2,6-DMNDC & $\mathrm{C}_{10} \mathrm{H}_{6}\left(\mathrm{CO}_{2} \mathrm{CH}_{3}\right)_{2}$ & 14 & $\mathrm{NA}$ & 210 & NA \\
BEB & $\mathrm{C}_{6} \mathrm{H}_{5} \mathrm{COOCH}_{2} \mathrm{C}_{6} \mathrm{H}_{5}$ & 14 & 50 & 30 & $0.17 \pm 0.01$ \\
PHB & $\mathrm{C}_{6} \mathrm{H}_{5} \mathrm{CO}_{2} \mathrm{C}_{6} \mathrm{H}_{5}$ & 13 & 50 & 90 & $0.17 \pm 0.01$ \\
DiMeOHTe & $\mathrm{C}_{6} \mathrm{H}_{4}-1,4-\left(\mathrm{CO}_{2} \mathrm{CH}_{3}\right)_{2}$ & 10 & $\mathrm{NA}$ & 160 & NA \\
AnAc & $\mathrm{CH}_{3} \mathrm{CO}_{2} \mathrm{CH}_{2} \mathrm{C}_{6} \mathrm{H}_{4}-4-\left(\mathrm{OCH}_{3}\right)$ & 9 & 45 & 30 & $0.19 \pm 0.01$ \\
Me-2-MeBe & $\mathrm{CH}_{3} \mathrm{OC}_{6} \mathrm{H}_{4} \mathrm{CO}_{2} \mathrm{CH}_{3}$ & 9 & 50 & 30 & $0.19 \pm 0.01$ \\
Me-2-Fu & $\mathrm{C}_{6} \mathrm{H}_{6} \mathrm{O}_{3}$ & 6 & 45 & 30 & $0.20 \pm 0.01$ \\
\hline
\end{tabular}

The thermal conductivity of materials is known to be influenced by several parameters (e.g., chemical bonds, chain orientation, crystallinity, molecular weight, crosslinking) [32]. Although their thermal conductivities could not be directly measured, DiMeOHTe and 2,6-DMNDC present similar chemical structures, bonds and molecular weights to the other esters are presented hereby, which leads to the assumption that comparable $\lambda \leq 0.2 \mathrm{~W} /(\mathrm{m} \cdot \mathrm{K})$ are to be expected. Additionally, the $\lambda$ of polyethylene terephthalate and naphthalene, which have similar structures to DiMeOHTe and 2,6-DMNDC, amount to 0.15 [33] and $0.11 \mathrm{~W} /(\mathrm{m} \cdot \mathrm{K})$ [34], respectively. This is also in accordance with the hypothesis stated above.

While values of $0.2 \mathrm{~W} /(\mathrm{m} \cdot \mathrm{K})$ are considered low for other applications, they are regarded as average values for LHS applications. If deemed necessary by the specific LHS application, several 
methods to increase the $\lambda$ of PCMs have been tested. For example, by adding $0.06 \mathrm{wt} \%$ nanographite to a paraffin-based PCM, Sun et al. [35] increased the thermal conductivity of approximately $25 \%$. Alternatively, Lazzarin et al. [36] achieved six times faster discharge times using aluminum foams as heat transfer mediums. Preliminary studies on the usage of finned-tube heat exchangers to deliver high power and grant a higher thermal conductivity also seem to be promising [37-39].

\subsection{Natural Occurrence and Toxicity}

Aromatic esters and aromatic compounds, in general, often present the disadvantage of being toxic or not sustainable to the environment [40]. For example, naphthalene and naphthalene-derived compounds occur in nature in crude oil and coal tar, and, as such, are not derived from sustainable sources. Additionally, they are often toxic to the aquatic life with long-lasting effects[41].

DiMeOHTe, PHB, DBO, 2,6-DMNDC and Me-2-MeBe do not occur in nature, but are currently widely used in a variety of industrial applications. For example, DiMeOHTe and 2,6-DMNDC are both important precursors for the industrial production of Polyethylene Terephthalate (PET) and Polyethylene Naphthalate (PEN) plastics [20,21], PHB is employed as a starting material for the production of optical products such as lenses [42], and Me-2-MeBe constitutes a component of several fragrances [18].

However, not all aromatic compounds are toxic or do not occur in nature. For example, Me-2-Fu, $B E B$ and AnAc occur widely in nature in cocoa plants, wood and several types of berries, respectively. $\mathrm{Me}-2-\mathrm{Fu}$ and AnAc are both used as flavouring food additives [18], while BEB is a common pharmaceutical employed to treat skin diseases [43].

None of the compounds studied here are reported to possess acute toxicity, but they might cause mild irritation reactions to the skin and respiratory traits, as reported by the safety data sheets.

All the aromatic esters that do occur in nature showed a high degree of polymorphism and, as such, their $\Delta H$ could not be determined. However, due to their bio-nature, it would be interesting to evaluate their polymorphism and $\Delta H$ in further studies.

2,6-DMNDC and DiMeOHTe represent the most interesting candidates in terms of phase change transition properties and density for high-temperature applications, however, they do not occur in nature and are both constituents of plastics. This represents a disadvantage and might halt their development as PCMs. Nevertheless, some decomposition routes of PET and PEN from which they could be extracted are currently being studied [44]. This would promote the recycling of plastics and would prove to be beneficial to future sustainability.

\section{Conclusions and Outlook}

In this study, the thermal properties of eight commercial aromatic esters, namely Dibenzyl oxalate (DBO), Dimethyl-2,6-naphthalene dicarboxylate (2,6-DMNDC), Anysil acetate (AnAc), Methyl-2-methoxybenzoate (Me-2-MeBe), Benzyl benzoate (BEB), Dimethyl terephthalate (DiMeOHTe), Methyl-2-furoate (Me-2-Fu) and Phenyl benzoate (PHB) have been investigated with regards to thermal energy storage applications. In particular, the aromatic esters were assessed as possible PCMs based on their phase change temperatures $T_{c}$ and $T_{m}$, enthalpies of fusion $\Delta H$, densities $\rho$, thermal conductivities $\lambda$, toxicities and natural occurrences.

The aromatic esters selected show a wide range of $T_{m}$ from $-15.7^{\circ} \mathrm{C}$ for AnAc to $190.2{ }^{\circ} \mathrm{C}$ for 2,6-DMNDC. It was not possible to determine the $T_{c}$ and $T_{m}$ of Me-2-MeBe, since no crystallization was observed in the DSC due to either very low melting points or a large degree of supercooling or a combination of both.

The gravimetric $\Delta H$ measured range from a minimum of $97.7 \mathrm{~J} / \mathrm{g}$ for Me-2-Fu to a maximum of $158.4 \mathrm{~J} / \mathrm{g}$ for 2,6-DMNDC. While such values are generally considered as low to medium for LHS applications, all aromatic esters possess $\rho>1 \mathrm{~g} / \mathrm{mL}$, which grant higher volumetric storage densities $(\mathrm{J} / \mathrm{mL})$. The $\Delta H$ of BEB and AnAc could not be determined due to the presence of polymorphism and solid-solid transformations. While the study of their polymorphic behaviour exceeds the scope of this 
investigation at this time, the authors will conduct more intensive investigations on the polymorphism of esters in the near future.

The $\lambda$ observed in the liquid phase are similar to those of other organics between $0.155 \mathrm{~W} /(\mathrm{m} \cdot \mathrm{K})$ and $0.203 \mathrm{~W} /(\mathrm{m} \cdot \mathrm{K})$.

Concerning the degradation temperatures, the aromatic esters are completely degraded by $350{ }^{\circ} \mathrm{C}$, with the exception of DBO, which degrades fully at $530{ }^{\circ} \mathrm{C}$. DiMeOHTe and 2,6-DMNDC present $T_{\text {degr onset }}$ close to their $T_{m}$, which might be detrimental to their long-term stability.

In general, no trend correlating the carbon number to the $T_{m}$ was observed. However, some correlation between the $T_{m}$ and the chemical structures could be noticed. In particular, those aromatic esters characterized by the presence of aromatic rings at the extremities of the molecule, such as PHB, BEB and DBO, show lower $T_{m}$ than expected given their carbon numbers. This is thought to be due to the rotational freedom of end-groups, which causes disruptions in the crystal lattice. On the contrary, aromatic rings in the middle of the molecule (2,6-DMNDC and DiMeOHTe) seem to render the compounds more stable, as characterized by higher $T_{m}$. Some of these effects are also visible in the thermal stability of the esters.

Amongst the esters presented hereby, DiMeOHTe, 2,6-DMNDC and DBO represent the most interesting candidates with $T_{m}>70{ }^{\circ} \mathrm{C}$ and volumetric $\Delta H>150 \mathrm{~J} / \mathrm{mL}$. This is especially true for high-temperature applications, where not many other organic materials are found [45]. Concerning the other aromatic esters, more attractive PCMs with higher enthalpies exist in the same temperature range.

While DiMeOHTe, 2,6-DMNDC and DBO's thermal conductivites are relatively low and similar to those of other organic PCMs $(\leq 0.2 \mathrm{~W} /(\mathrm{m} \cdot \mathrm{K}))$, several studies in the literature have proposed various methods to enhance the thermal conductivity of organic materials.

However, all three compounds present some disadvantages that need to be taken into account in view of possible LHS applications. First, all three compounds are of synthetic nature and do not occur in nature. DiMeOHTe and 2,6-DMNDC could potentially be extracted by recycled PET and PEN plastics, as proved by some studies, which would contribute to the sustainability of future energy applications. Additionally, DiMeOHTe and 2,6-DMNDC present $T_{\text {degr onset }}$ close to their melting points. In order to determine the impact this could have on the usage of these materials in a LHS, the exact mechanisms behind such degradation would have to be evaluated, and longer term stability studies would have to be perfomed. Generally, in order to ensure the introduction of aromatic esters in LHS setups and ensure their suitability as PCMs, such issues will have to first be addressed.

At present, this exceeds the scope of the study presented, but will be further investigated by the authors in future studies.

Author Contributions: Conceptualization, R.R. and A.S.; Data curation, R.R.; Formal analysis, R.R.; Funding acquisition, L.J.F., J.W. and A.S.; Investigation, R.R.; Methodology, R.R.; Project administration, R.R. and A.S.; Resources, O.F.; Supervision, L.J.F., J.W. and A.S.; Validation, R.R.; Visualization, R.R.; Writing一original draft, R.R.; Writing-review and editing, R.R., J.W. and A.S. All authors have read and agreed to the published version of the manuscript.

Funding: This research was funded by the Swiss National Science Foundation (Schweizerischer Nationalsfonds für Förderung der Wissenschaftlichen Forschung SNSF, project number: PZENP2_173636.

Acknowledgments: This work was developed within the framework of the project DENSE "Direct-contact ENergy StoragE" funded by the Swiss National Science Foundation (SNSF, project number PZENP2_173636) with the support of the Swiss Competence Center for Energy Research Storage of Heat and Electricity (SCCER). The authors wish to thank Andreas Bach from METTLER TOLEDO for his assistance with the measurements of aromatic esters at $-150^{\circ} \mathrm{C}$ and Gabriel Rubio Perez from the Universidad de Burgos (ES) for his support on the THB measurements.

Conflicts of Interest: The authors declare no conflict of interest. 


\section{Abbreviations}

The following abbreviations are used in this manuscript:

2,6-DMNDC Dimethyl-2,6-Naphthalene Dicarboxylate

AnAc

BEB

DBO

Anisyl Acetate

DiMeOHTe

Benzyl Benzoate

DSC

I

LHS

Lit.

Dibenzyl Oxalate

Dimethyl Terephthalate

Differential Scanning Calorimetry

Measuring current [mA] (for Transient Hot Bridge)

Latent Heat Storage

$\mathrm{Me}-2-\mathrm{Fu}$

Literature

Me-2-MeBe

Methyl-2-Furoate

MW

NA

PCM

PET

PEN

PHB

RT

SNSF

$T_{\text {degr endset }}$

$T_{\text {degr onset }}$

TES

TGA

THB

Methyl-2-methoxybenzoate

Molecular Weight $[\mathrm{g} / \mathrm{mol}]$

Not Available

Phase Change Material

Polyethylene Terephthalate

Polyethylene Naphthalate

Phenyl Benzoate

Room Temperature

Swiss National Science Foundation

Endset degradation temperature $\left[{ }^{\circ} \mathrm{C}\right]$

Onset degradation temperature $\left[{ }^{\circ} \mathrm{C}\right]$

Thermal Energy Storage

Thermogravimetric Analysis

Transient Hot Bridge

Onset crystallization temperature $\left[{ }^{\circ} \mathrm{C}\right]$

$T_{C}$

Onset melting temperature $\left[{ }^{\circ} \mathrm{C}\right]$

Greek Symbols

$\Delta H$

$\lambda$

Gravimetric $[\mathrm{J} / \mathrm{g}]$, volumetric $[\mathrm{J} / \mathrm{mL}]$ or molar enthalpy of fusion $[\mathrm{kJ} / \mathrm{mol}]$

$\lambda$

$\rho$

Thermal conductivity $[\mathrm{W} /(\mathrm{m} \cdot \mathrm{K})]$

Density $[\mathrm{g} / \mathrm{mL}]$

\section{Appendix A. DSC curves of AnAc, BEB and Me-2-MeBe}

In this Appendix, the curves from the experiments performed with a DSC equipped with liquid nitrogen for AnAc (Figure A1), BEB (Figure A2) and Me-2-MeBe (Figure A3) are reported.

The esters were measured once. First, they are heated in the DSC with a cycle at $10 \mathrm{~K} / \mathrm{min}$ to ensure homogeneity, which is discarded during the evaluation. Then, they are cycled three times at 10 and $2 \mathrm{~K} / \mathrm{min}$ for a total of six cycles. The methodology is reported in detail in the related section.

All samples do not form stable crystalline structure but rather undergo cold crystallization as shown by the glass transition around $-80^{\circ} \mathrm{C}$. AnAc and BEB show polymorphism as both exothermic and endothermic peaks are seen during the heating of the sample. This did not allow to precisely calculate the $\Delta H$ of the esters.

Me-2-MeBe did not show any phase change beside the glass transition, therefore its $T_{m}$ and $T_{c}$ could not be determined. 


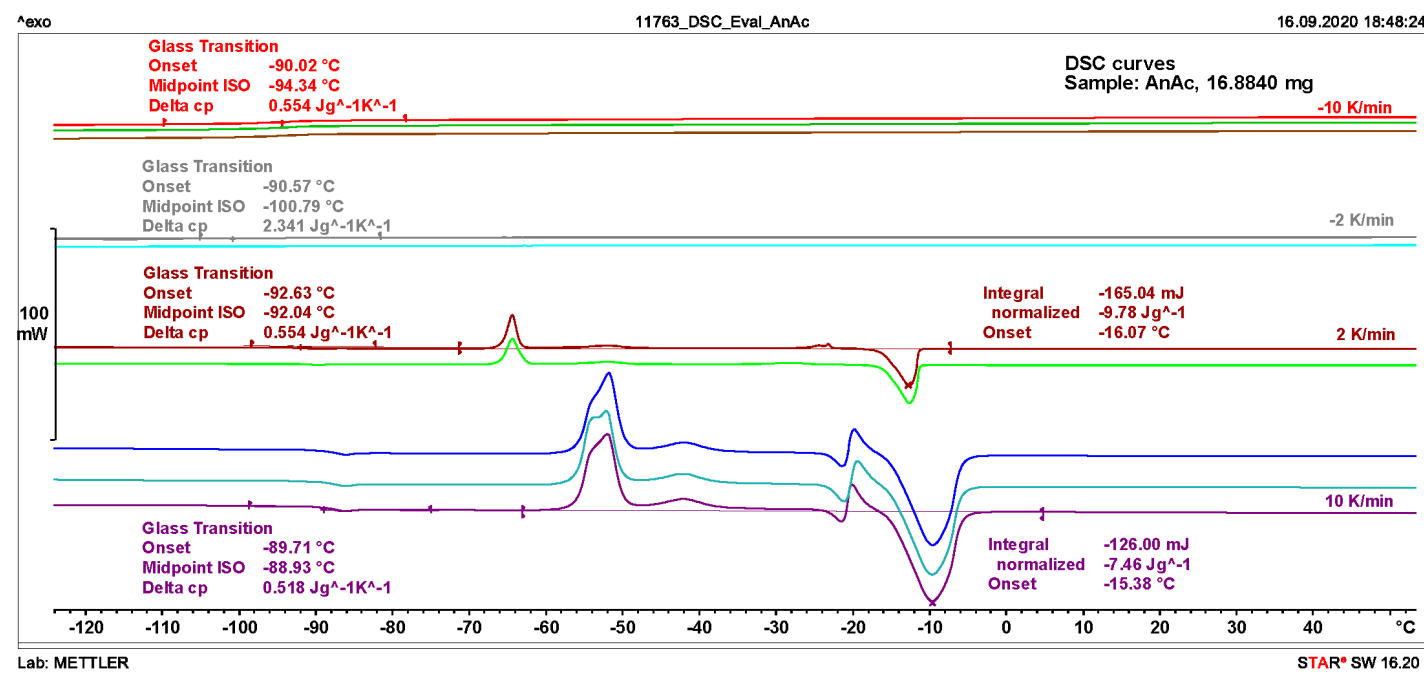

Figure A1. DSC data of AnAc.

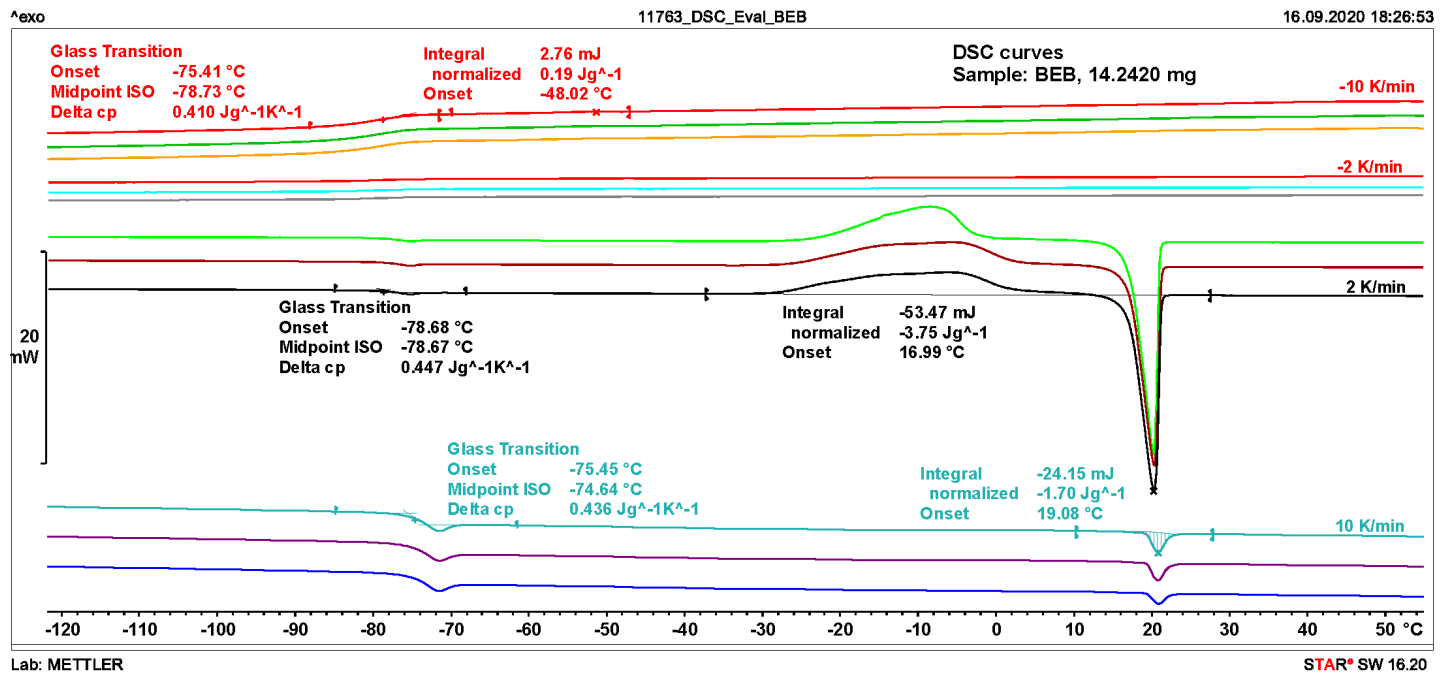

Figure A2. DSC data of BEB.

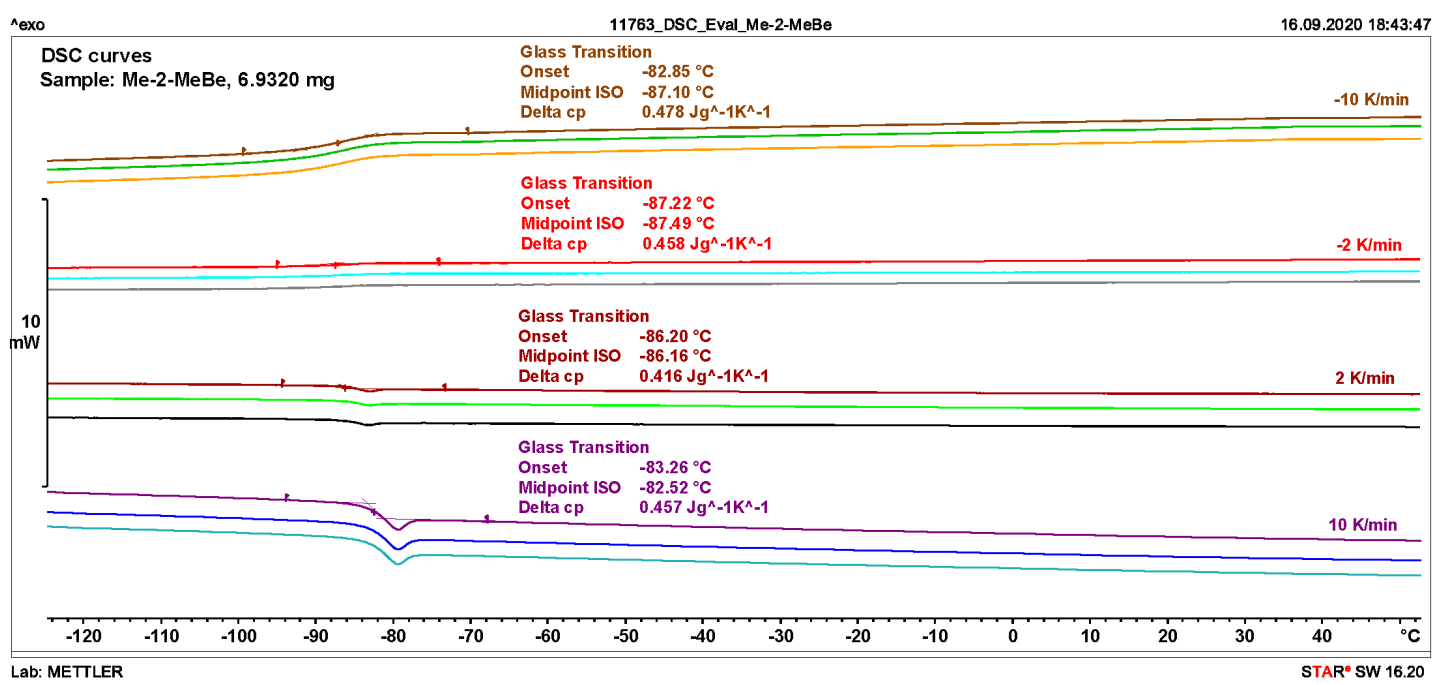

Figure A3. DSC data of Me-2-MeBe. 


\section{Appendix B. EasyMax Curves of BEB}

Since BEB was able to crystallize overnight at temperatures of $-20^{\circ} \mathrm{C}$, its lack of crystallization in the DSC was appointed to a large tendency to supercool due to small sample sizes. In order to evaluate its $T_{m}$ and $T_{c}$ with lower degrees of supercooling, BEB was cycled in the EasyMax 102, a thermal cycling unit, with the same method employed for DSC measurements, and with sample sizes of $5 \mathrm{~g}$. The experiment was repeated three times. An example of a heating/cooling experiment (three $10 \mathrm{~K} / \mathrm{min}$ and three $2 \mathrm{~K} / \mathrm{min}$ cycles) performed in the EasyMax for BEB is reported in Figure A4. While its $\Delta H$ could not be measured with this method, its $T_{m}$ and $T_{c}$ could be estimated at $18.1^{\circ} \mathrm{C}$ and $-19.1^{\circ} \mathrm{C}$ respectively.

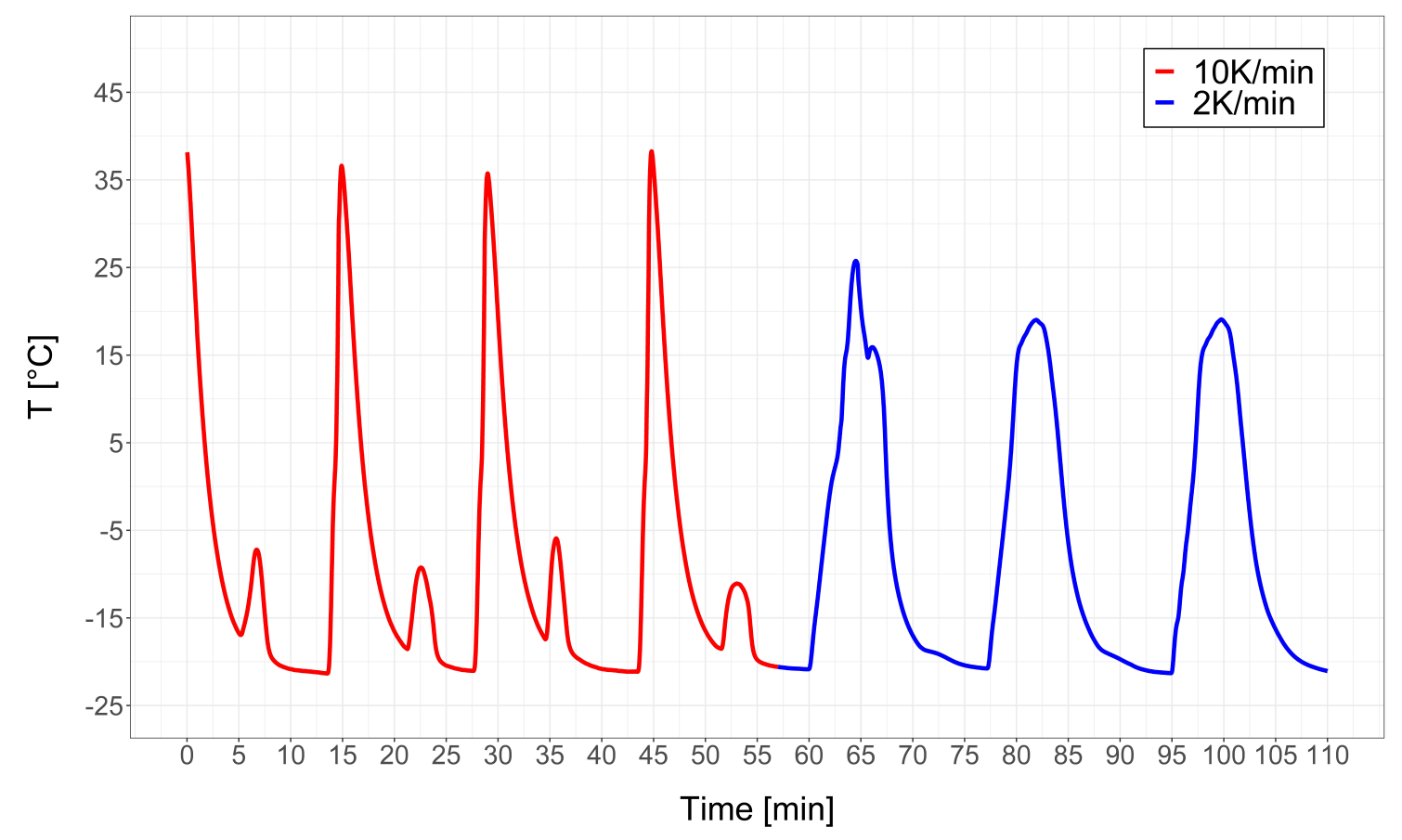

Figure A4. Example of BEB's thermal cycling in METTLER TOLEDO's EasyMax 102.

\section{Appendix C. TGA Curves}

The TGA curves of the aromatic esters studied are reported below. Each aromatic ester was analyzed three times in the TGA, however only one representative curve per sample is shown here for simplicity. All aromatic esters with the exception of DBO undergo one-step thermal degradation and show $T_{\text {degr onset }}$ between $67(\mathrm{Me}-2-\mathrm{Fu})$ and $220^{\circ} \mathrm{C}(2,6-\mathrm{DMNDC})$, and $T_{\text {degr endset }}$ from $213(\mathrm{Me}-2-\mathrm{Fu})$ to $530{ }^{\circ} \mathrm{C}(\mathrm{DBO})$. 


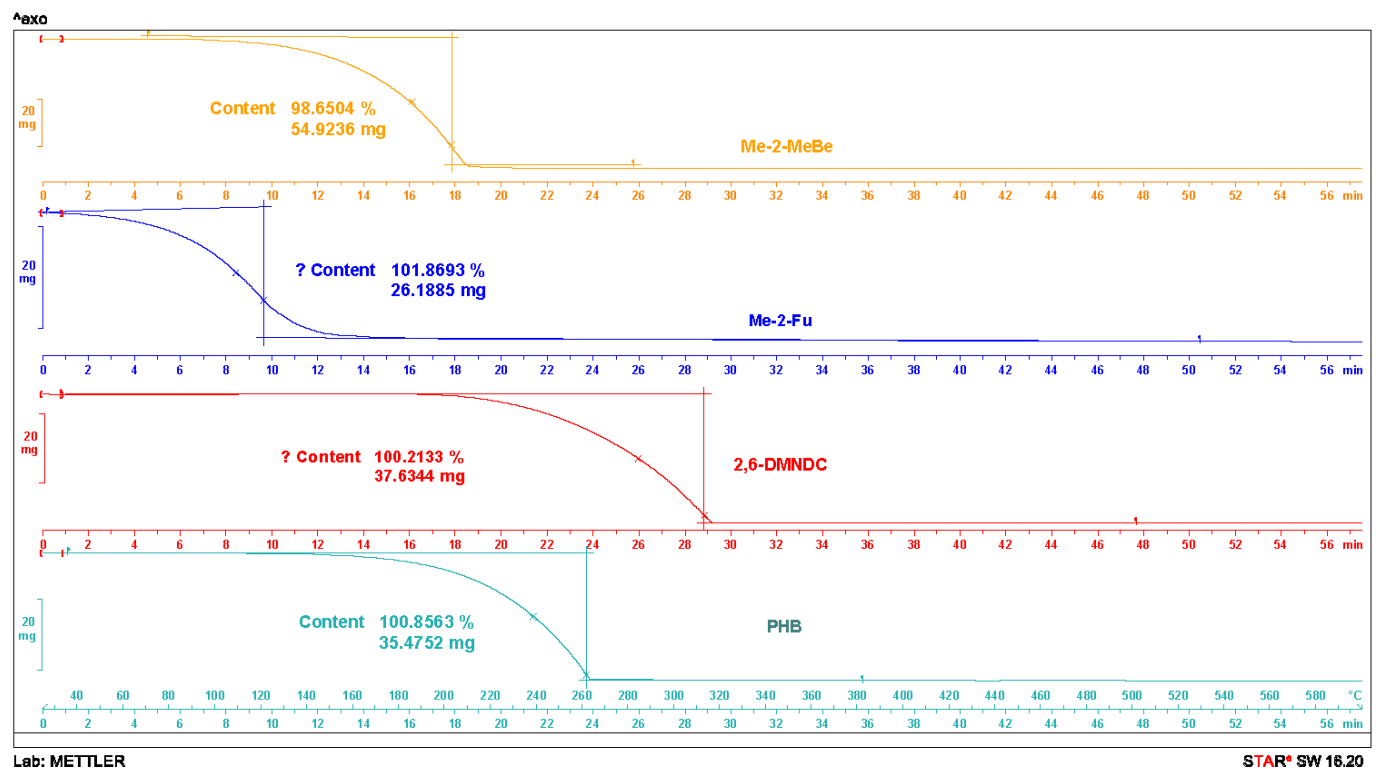

Figure A5. TGA data of Me-2-MeBe, Me-2-Fu, 2,6-DMNDC and PHB.

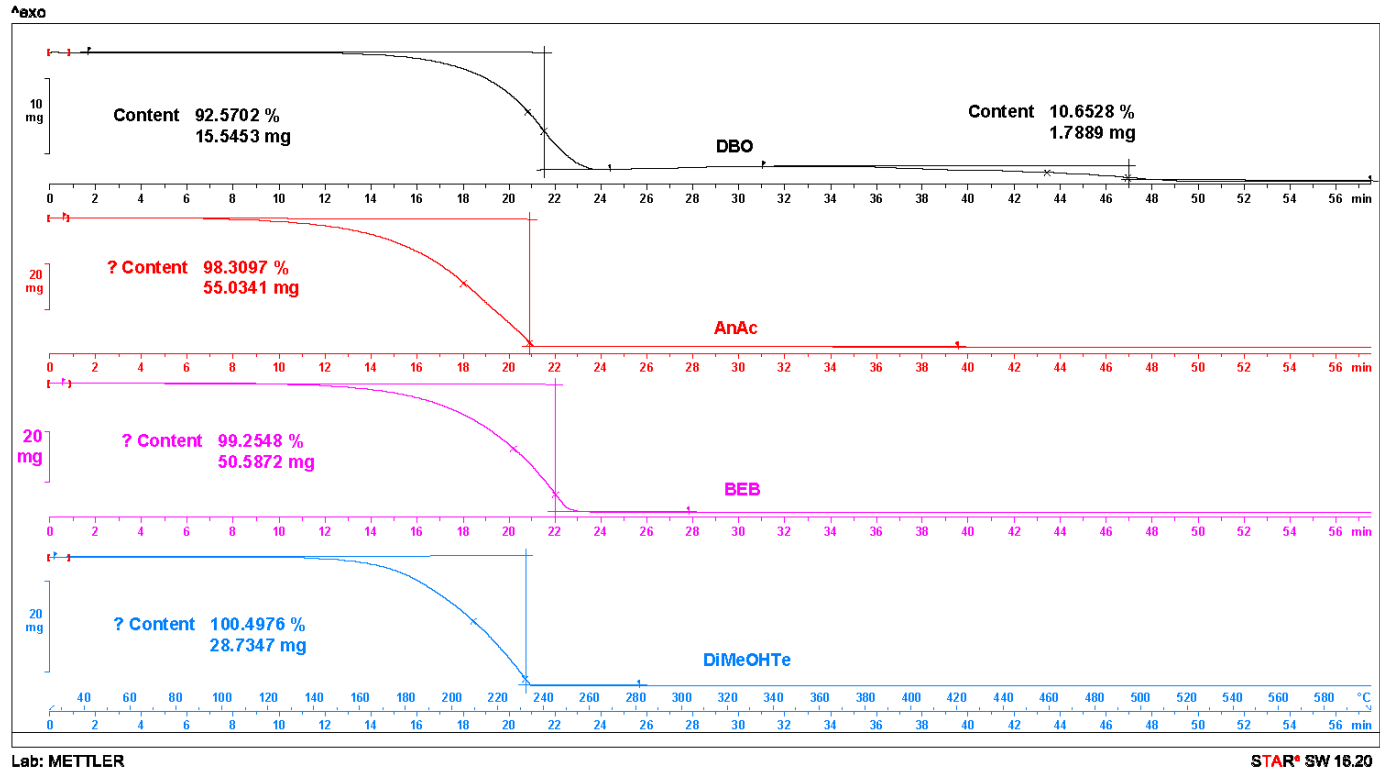

Figure A6. TGA data of DBO, AnAc, BEB and DiMeOHTe.

\section{References}

1. International Energy Agency IEA. Tracking Energy Integration, Paris. 2019. Available online: https://www. iea.org/reports/tracking-energy-integration (accessed on 20 August 2020).

2. International Energy Agency IEA. World Energy Outlook 2019, Paris. 2019. Available online: https: / / www.iea.org/reports/world-energy-outlook-2019 (accessed on 20 August 2020).

3. International Energy Agency IEA. Renewables 2019, Paris. 2019. Available online: https://www.iea.org/ reports / renewables-2019 (accessed on 20 August 2020).

4. Li, G.; Zheng, X. Thermal energy storage system integration forms for a sustainable future. Renew. Sustain. Energy Rev. 2016, 62, 736-757. [CrossRef]

5. Cabeza, L.; Mehling, H. Heat and Cold Storage with PCM: An up to Date Introduction into Basics and Applications; Springer: Berlin/Heidelberg, Germany, 2008; ISBN 9783540685562.

6. Magendran, S.S.; Khan, F.S.A.; Mubark, N.M.; Vaka, M.; Rashmi, W.; Khalid, M.; Abdullah, E.C.; Nizamuddin, S.; Karri, R.R. Synthesis of organic phase change materials (PCM) for energy storage applications: A review. Nano-Struct. Nano-Objects 2019, 20, 100399. [CrossRef] 
7. Gmelin, L. Handbuch der Chemie, Vol. 4: Handbuch der organischen Chemie; K. Winter: Heidelberg, Germany, 1848; ISBN 9781176030664.

8. Sari, A.; Bicer, A. Thermal energy storage properties and thermal reliability of some fatty acid esters/building material composites as novel form-stable PCMs. Sol. Energy Mater. Sol. Cells 2012, 101, 114-122. [CrossRef]

9. Stamatiou, A.; Obermeyer, M.; Fischer, L.J.; Schuetz, P.; Worlitschek, J. Investigation of unbranched, saturated, carboxylic esters as phase change materials. Renew. Energy 2017, 108, 401-409. [CrossRef]

10. Aydin, A.A.; Aydin, A. High-chain fatty acid esters of 1-hexadecanol for low temperature thermal energy storage with phase change materials. Sol. Energy Mater. Sol. Cells 2012, 96, 93-100. [CrossRef]

11. Ravotti, R.; Fellmann, O.; Lardon, N.; Fischer, L.J.; Stamatiou, A.; Worlitschek, J. Synthesis and Investigation of Thermal Properties of Highly Pure Carboxylic Fatty Esters to Be Used as PCM. Appl. Sci. 2018, 8, 1069. [CrossRef]

12. Ravotti, R.; Fellmann, O.; Lardon, N.; Fischer, L.J.; Stamatiou, A.; Worlitschek, J. Analysis of Bio-Based Fatty Esters PCM's Thermal Properties and Investigation of Trends in Relation to Chemical Structures. Appl. Sci. 2019, 9, 225. [CrossRef]

13. Lutton, E.S.; Fehl, A.J. The polymorphism of odd and even saturated single acid triglycerides, C8-C22. Lipids 1970, 5, 90-99. [CrossRef]

14. Hernqvist, L. Polymorphism of Triglycerides a Crystallographic Review. J. Food Struct. 1990, 9, 39-44.

15. Moorty, A.S.; Liu, R.; Mazzanti, G.; Wesdorp, L.H.; Marangoni, A.G. Estimating Thermodynamic Properties of Pure Triglyceride Systems Using the Triglyceride Property Calculator. J. Am. Oil Chem. Soc. 2016, 94, 187-199. [CrossRef]

16. Hunter, C.A.; Sanders, J.K.M. The nature of $\pi-\pi$ interactions. J. Am. Chem. Soc. 1990, 112, 5525-5534. [CrossRef]

17. Ravotti, R.; Fellmann, O.; Fischer, L.J.; Stamatiou, A.; Worlitschek, J. Investigation of the Thermal Properties of Diesters from Methanol, 1-Pentanol, and 1-Decanol as Sustainable Phase Change Materials. Materials 2020, 13, 810. [CrossRef] [PubMed]

18. Burdock, G.A. Fenaroli's Handbook of Flavor Ingredients, 6th ed.; CRC Press: Boca Raton, FL, USA, 2009; ISBN 9781420090772.

19. Fahlbusch, K.G.; Hammerschmidt, F.J.; Panten, J.; Pickenhagen, W.; Schatkowski, D.; Bauer, K.; Garbe, D. and Surburg, H. Flavors and Fragrances. In Ullmann's Encyclopedia of Industrial Chemistry; Wiley-VCH Verlag GmbH and Co.: Weinheim, Germany, 2003; ISBN 9783527306732

20. Kurokawa, H.; Ohshima, M.; Sugiyama, K.; Miura, H. Methanolysis of polyethylene terephthalate (PET) in the presence of aluminium tiisopropoxide catalyst to form dimethyl terephthalate and ethylene glycol. Polym. Degrad. Stab. 2003, 79, 529-533. [CrossRef]

21. Lillwitz, L.D. Production of dimethyl-2,6-naphthalenedicarboxylate: Precursor to polyethylene naphthalate. J. Am. Chem. Soc. 1990, 221, 337-358. [CrossRef]

22. Otake, S.; Yoda, S. Decomposition of Polyethylene 2,6-Naphthalene Dicarboxylate to Constituent Monomers Using Supercritical Methanol. Polym. J. 1999, 31, 714-716.

23. Castellón, C.; Günther, E.; Mehling, H.; Hiebler, S. and Cabeza, L.F.; Determination of the enthalpy of PCM as a function of temperature using a heat-flux DSC - A study of different measurement procedures and their accuracy. Int. J. Energy Res. 2008, 32, 1258-1265. [CrossRef]

24. Perkin Elmer Guide. Introduction to Thermogravimetric Analysis. Available online: https: / / www.perkinelmer.com/lab-solutions / resources/docs / faq_beginners-guide-to-thermogravimetricanalysis_009380c_01.pdf (accessed on 21 August 2020).

25. Linseis Workshop. Measuring Thermal Conductivity of PCMs. Available online: https://thermalmaterials. org/workshops/workshop_thermalconductivity2015/presentations/transient-hot-bridge/at_download/ file (accessed on 15 March 2020)

26. Dreisbach, R.R. Physical Properties of Chemical Compounds. Adv. Chem. 1961, 22, 3-486. [CrossRef]

27. Bunn, C.W. The melting points of chain polymers. J. Polym. Sci. 1996, 34, 799-819. [CrossRef]

28. Clar, E.; Kemp, W.; Stewart, D.G. The significance of Kekulé structures for the stability of aromatic systems. Tetrahedron 1957, 3, 325-333. [CrossRef]

29. Sarbu, I.; Sebarchievici, C. A Comprehensive Review of Thermal Energy Storage. Sustainability 2018, 10, 191. [CrossRef] 
30. Trahanovsky, S.W.; Ong, C.C.; Pataky, J.G.; Weitl, F.L.; Muellen, P.W.; Clardy, J.C.; Hansen, R.S. Organic oxalates. VI. Pyrolysis of di(.alpha.-substituted)benzyl oxalates. J. Org. Chem. 1971, 36, 3575-3579. [CrossRef]

31. Zmywaczyk, J.; Zbińkowski, P.; Smogór, H.; Olejnik, A.; Koniorczyk, P. Cooling of High-Power LED Lamp Using a Commercial Paraffin Wax. Int. J. Thermophys. 2017, 38, 1-14. [CrossRef]

32. Wei, X.; Luo, T. Chain length effect on thermal transport in amorphous polymers and a structure-thermal conductivity relation. Phys. Chem. Chem. Phys. 2019, 21, 15523-15530. [CrossRef] [PubMed]

33. Speight, J.G.; Lange, N.A. Lange's Handbook of Chemistry; 16th ed.; McGraw-Hill: New York, NY, USA, 2005; pp. 2758-2807, ISBN 0-07-143220-5.

34. Bogatov, G.F.; Lapin, V.B.; Rastorguev Yu, L. Thermal Conductivity of Naphthalene Hydrocarbons in the Liquid State. I. Naphthalene and Methylnaphthalene. Viniti 1987, 1-15. Available online: http:/ /www.ddbst. com/en/EED/PCP/TCN_C123.php (accessed on 10 September 2020).

35. Sun, X.; Liu, L.; Mo, Y.; Li, J.; Li, C. Enhanced thermal energy storage of a paraffin-based phase change material (PCM) using nano carbons. Appl. Therm. Eng. 2020, 181, 115992. [CrossRef]

36. Lazzarin, R.M.; Mancin, S.; Noro, M.; Righetti, G. Hybrid PCM-aluminium foams' thermal storages: An experimental study. Int. J. Low-Carbon Technol. 2018, 13, 286-291. [CrossRef]

37. Delgado, W.; Stamatiou, A.; Maranda, S.; Waser, R.; Worlitschek, J. Assessment of High Power Latent Heat Storage Solutions. In Proceedings of the Eurotherm Seminar 112 Advances in Thermal Energy Storage, Lleida, Spain, 15-17 May 2019; ISBN 978-84-9144-155-7.

38. Amagour, M.E.H.; Rachek, A.; Bennajah, M.; Ebn Touhami, M. Experimental investigation and comparative performance analysis of a compact finned-tube heat exchanger uniformly filled with a phase change material for thermal energy storage. Energy Convers. Manag. 2018, 165, 137-151. [CrossRef]

39. Waser, R.; Maranda, S.; Stamatiou, A.; Zaglio, M.; Worlitschek, J. Modeling of solidification including supercooling effects in a fin-tube heat exchanger based latent heat storage. Sol. Energy 2020, 200, 10-21. [CrossRef]

40. Agency for Toxic Substances and Disease Registry (ATSDR). Case Studies in Environmental Medicine Toxicity of Polycyclic Aromatic Hydrocarbons (PAHs). 2009. Available online: https://www.atsdr.cdc.gov/ csem/pah/docs/pah.pdf (accessed on 5 May 2020).

41. Baali, A.; Yahyaoui, A. Polycyclic Aromatic Hydrocarbons (PAHs) and Their Influence to Some Aquatic Species. In Biochemical Toxicology—Heavy Metals and Nanomaterials; IntechOpen: London, UK, 2019. [CrossRef]

42. Wilderbeek, H.T.A.; Van der Meer, M.G.M.; Jansen, M.A.G.; Nelissen, L.; Fischer, H.R.; Van Es, S.; Bastiaansen, C.W.M.; Lub, J.; Broer, D. Synthesis and properties of phenyl benzoate-based and biphenyl-based liquid crystalline thiol-ene monomers. Liq. Cryst. Chem. 2010, 1, 93-108. [CrossRef]

43. World Health Organization. World Health Organization Model List of Essential Medicines: 21st List; World Health Organization: Geneva, Switzerland, 2019. Available online: https://apps.who.int/iris/bitstream/ handle/10665/325771/WHO-MVP-EMP-IAU-2019.06-eng.pdf?sequence=1\&isAllowed=y (accessed on 1 February 2020).

44. Fakhrpour, G.; Bagheri, S.; Golriz, M.; Shekari, M. Degradation kinetics of PET/PEN blend nanocomposites using differential isoconversional and differential master plot approaches. J. Therm. Anal. Calorim. 2016, 124, 917-924. [CrossRef]

45. Farid, M.; Khudhair, S.; Razack, S.; Al-Hallaj, S. A review on phase change energy storage: materials and applications. Energy Convers. Manag. 2004, 45, 1597-1615. [CrossRef]

(c) 2020 by the authors. Licensee MDPI, Basel, Switzerland. This article is an open access article distributed under the terms and conditions of the Creative Commons Attribution (CC BY) license (http://creativecommons.org/licenses/by/4.0/). 